\title{
NAD(P)H Fluorescence Imaging of Postsynaptic Neuronal Activation in Murine Hippocampal Slices
}

\author{
C. William Shuttleworth, Angela M. Brennan, and John A. Connor \\ Department of Neurosciences, University of New Mexico School of Medicine, Albuquerque, New Mexico 87131
}

We examined mechanisms contributing to stimulus-evoked changes in $\mathrm{NAD}(\mathrm{P}) \mathrm{H}$ fluorescence as a marker of neuronal activation in area CA1 of murine hippocampal slices. Three types of stimuli (electrical, glutamate iontophoresis, bath-applied kainate) produced biphasic fluorescence changes composed of an initial transient decrease ("initial component," 1-3\%), followed by a longer-lasting transient increase ("overshoot," 3-8\%). These responses were matched by inverted biphasic flavin adenine dinucleotide (FAD) fluorescence transients, suggesting that these transients reflect mitochondrial function rather than optical artifacts. Both components of $\mathrm{NAD}(\mathrm{P}) \mathrm{H}$ transients were abolished by ionotropic glutamate receptor block, implicating postsynaptic neuronal activation as the primary event involved in generating the signals, and not presynaptic activity or reuptake of synaptically released glutamate. Spatial analysis of the evoked signals indicated that the peak of each component could arise in different locations in the slice, suggesting that there is not always obligatory coupling between the two components. The initial $\mathrm{NAD}(\mathrm{P}) \mathrm{H}$ response showed a strong temporal correspondence to intracellular $\mathrm{Ca}^{+}$increases and mitochondrial depolarization. However, despite the fact that removal of extracellular $\mathrm{Ca}^{2+}$ abolished neuronal cytosolic $\mathrm{Ca}^{2+}$ transients to exogenous glutamate or kainate, this procedure did not reduce slice NAD(P)H responses evoked by either of these agonists, implying that mechanisms other than neuronal mitochondrial $\mathrm{Ca}^{2+}$ loading underlie $\operatorname{slice} \mathrm{NAD}(\mathrm{P}) \mathrm{H}$ transients. These data show that, in contrast to previous proposals, slice $\mathrm{NAD}(\mathrm{P}) \mathrm{H}$ transients in mature slices do not reflect neuronal Ca ${ }^{2+}$ dynamics and demonstrate that these signals are sensitive indicators of both the spatial and temporal characteristics of postsynaptic neuronal activation in these preparations.

Key words: NADH; optical imaging; mitochondria; oxidative metabolism; hippocampus; calcium; glutamate; postsynaptic excitation; intrinsic signals; $\mathrm{Na}^{+} / \mathrm{K}^{+}$ATPase; ouabain

\section{Introduction}

Interest in noninvasive indicators of neuronal electrical activity has been ongoing for several decades and includes studies of birefringence, light scattering (Hill and Keynes, 1949; Cohen et al., 1968), and plasmalemma-associated dyes (Cohen et al., 1974; Salzberg, 1989; Shoham et al., 1999). Starting with the "slow" measurements of Blasdel and Salama (1986) reporting what proved mostly to be intrinsic absorbance changes of hemoglobin in CNS tissue with intact circulation, measurements of integrated neuronal activity have come increasingly into the forefront of noninvasive optical measurements (Grinvald et al., 1986; Frostig et al., 1990; Luo and Katz, 2001). Other intrinsic monitoring loci, possibly more sensitive and not dependent on the presence of hemoglobin, are also available and at present are underexploited. These include monitoring the fluorescence of key components of oxidative phosphorylation, nicotinamide adenine dinucleotide (NADH).

$\mathrm{NADH}$ is the predominant component of tissue autofluorescence under UV excitation, but after donation of electrons to the electron transport chain, the oxidized molecule $\left(\mathrm{NAD}^{+}\right)$is nonfluorescent. Thus changes in NADH fluorescence long have been

Received July 19, 2002; revised Jan. 22, 2003; accepted Jan. 28, 2003.

This work was supported by National Institutes of Health Grants NS43458, NS35644, and RR15636. We thank H. Xing for assistance with the fura-2 experiments.

Correspondence should be addressed to Dr. C. William Shuttleworth, Department of Neurosciences, University of New Mexico School of Medicine, Basic Medical Sciences Building, Room 145, 915 Camino de Salud Northeast, Albuquerque, NM 87131. E-mail: bshuttleworth@salud.unm.edu.

Copyright $\odot 2003$ Society for Neuroscience $\quad 0270-6474 / 03 / 233196-13 \$ 15.00 / 0$ used as a measure of oxidative phosphorylation changes (Chance et al., 1962; Connor et al., 1976; Mayevsky et al., 1988). Signals are attributable primarily to mitochondrial NADH dynamics but can be referred to as $\mathrm{NAD}(\mathrm{P}) \mathrm{H}$ transients, because the fluorescence profile of NADPH is indistinguishable from that of NADH (Schuchmann et al., 2001). The usefulness of NAD(P)H fluorescence measurements for monitoring intense and coordinated CNS activation has been demonstrated during seizures (Jöbsis, 1971; O'Connor et al., 1972) or putative spreading depression produced by cerebral ischemia (Mayevsky et al., 1998; Rex et al., 1999; Hashimoto et al., 2000; Strong et al., 2000). In brain slice preparations the seizure-like bursting activity in hippocampus (Schuchmann et al., 1999; Kovacs et al., 2001) or burst discharges in respiratory neurons (Mironov and Richter, 2001) are accompanied by biphasic NAD $(\mathrm{P}) \mathrm{H}$ changes in which an initial transient $\mathrm{NAD}(\mathrm{P}) \mathrm{H}$ decrease is followed by a longer-lasting $\mathrm{NAD}(\mathrm{P}) \mathrm{H}$ increase. It has been suggested that these signals in slices are a consequence of stimulus-induced $\mathrm{Ca}^{2+}$ influx, $\mathrm{Ca}^{2+}$ dependent production of reactive oxygen species (ROS) production, and stimulation of citric acid cycle enzymes (Kovacs et al., 2001; Schuchmann et al., 2001). Whether such mechanisms would produce resolvable signals after less intense stimuli is not known, and the requirement for $\mathrm{Ca}^{2+}$ influx in these signals has not been examined previously in hippocampal slice preparations.

In the present study we have investigated $\mathrm{NAD}(\mathrm{P}) \mathrm{H}$ fluorescence transients in murine hippocampal slices. Robust signals were observed even with very modest presynaptic inputs, and we conclude that, contrary to previous assertions, there is no neces- 
sity for an increase in intracellular $\mathrm{Ca}^{2+}$ to generate the biphasic transients. A CCD imaging-based approach was used in this study, which permitted investigation of the spread of signals and also the spatial relationship between components of biphasic $\mathrm{NAD}(\mathrm{P}) \mathrm{H}$ signals. From these data and pharmacological analysis of evoked NAD $(\mathrm{P}) \mathrm{H}$ transients we conclude that these signals can provide a sensitive $\mathrm{Ca}^{2+}$-independent monitor of spatial as well as temporal aspects of physiological postsynaptic neuronal activation in slice.

\section{Materials and Methods}

Slice preparation. Male mice (C57BL/10J or C57BL/6J) were obtained from Jackson Laboratories (Bar Harbor, ME) at 4-6 weeks of age and were housed in standard conditions ( $12 \mathrm{hr}$ light/dark cycle) before death. Numbers in the study refer to numbers of slices, with a maximum of two slices obtained from an individual experimental animal used for each protocol. Mice were anesthetized deeply with a mixture of ketamine and xylazine (85 and $15 \mathrm{mg} / \mathrm{ml}$, respectively; $150 \mathrm{ml}$, s.c.) and decapitated. Brains were removed and placed in ice-cold cutting solution (see below for composition). Coronal sections $(350 \mu \mathrm{m})$ were cut with a Vibratome (Technical Products International, St. Louis, MO), and slices were transferred into room temperature ACSF (see below). Cutting and recording solutions were both $300-305 \mathrm{mOsm} / 1$. After being warmed to $34^{\circ} \mathrm{C}$ and held for $1 \mathrm{hr}$, ACSF was changed again, and the slices were held at room temperature until used for recording. Individual slices were transferred to the recording chamber and were perfused with warmed $\left(34^{\circ} \mathrm{C}\right)$, oxygenated ACSF at $2 \mathrm{ml} / \mathrm{min}$.

$N A D(P) H$ and flavin adenine dinucleotide fluorescence imaging. NADH has broad excitation and emission spectra with peaks at $\sim 350$ and 460 $\mathrm{nm}$, respectively. Excitation $(360 \mathrm{~nm})$ was delivered via a fiber optic/ monochromator system (Polychrome IV; Till Photonics, Gräfelfing, Germany) reflected onto the slice surface via a dichroic mirror (DMLP 400 nm, Chroma Technology, Brattleboro, VT). Fluorescence emission was collected by using a cooled interline transfer CCD camera (IMAGO, Till Photonics). All experiments used a $410 \mathrm{~nm}$ long-pass glass filter between the dichroic mirror and camera to maximize light capture. Pilot experiments that used a $450 \pm 15 \mathrm{~nm}$ interference filter showed that there was insignificant distortion from longer wavelength emitters. Flavin adenine dinucleotide (FAD) is the oxidized form of another electron carrier, $\mathrm{FADH}_{2}$, generated by tricarboxylic acid (TCA) cycle activity and oxidized in the electron transport chain. Unlike NADH, $\mathrm{FADH}_{2}$ is not fluorescent, but FAD displays green fluorescence after excitation in the blue range. Consequently, FAD fluorescence signals should be opposite in sign to $\mathrm{NAD}(\mathrm{P}) \mathrm{H}$ changes if these signals reflect mitochondrial metabolism. Changes in the FAD fluorescence were monitored by using excitation at $450 \mathrm{~nm}$, and emission was detected by using a 535 (50 BW) interference filter. Photobleaching was not significant for $\mathrm{NAD}(\mathrm{P}) \mathrm{H}$ measurements. For FAD measurements the photobleaching was noticeable, and data were corrected by fitting a first-order regression to prestimulus periods and subtracting extrapolated values from raw data. Absorbance of $360 \mathrm{~nm}$ excitation by solutions of carbonyl cyanide 4-(trifluoromethoxy)phenyl hydrazone (FCCP) was concentrationdependent and appreciable at $5 \mu \mathrm{M}$, producing an immediate $3-5 \%$ decrease in slice fluorescence when excited at this wavelength. This slightly depressed baseline was used in computing subsequent $\mathrm{NAD}(\mathrm{P}) \mathrm{H}$ fluorescence changes. FCCP absorbance was negligible at $450 \mathrm{~nm}$.

Imaging was performed after focusing onto the surface of slices, using either $10 \times$ or $40 \times$ water immersion objectives (numerical apertures 0.3 and 0.8 , respectively; Olympus), and collected after $2 \times 2$ binning of the $640 \times 480$ line image. After binning, individual pixels corresponded to areas of 2.6 and $0.64 \mu \mathrm{m}^{2}$ for $10 \times$ and $40 \times$ objectives, respectively. For analysis the image data were filtered by using $3 \times 3$ pixel averaging and presented as the change in fluorescence intensity/prestimulus fluorescence intensity $\left(\Delta F / F_{\mathrm{o}}\right)$. Mean camera background was $421 \pm 23.3$ $($ mean $\pm \mathrm{SD})$ arbitrary fluorescence units (AFU)/sec. With the use of a $10 \times$ objective the slice fluorescence attributable to $\mathrm{NAD}(\mathrm{P}) \mathrm{H}$, measured in stratum pyramidale, was $\sim 700 \mathrm{AFU} / \mathrm{sec}$. Integration times for data collection were between 100 and $150 \mathrm{msec}$. For display the selected im- ages were converted to "tif" format and exported to NIH Image (v1.62). Then they were put through the median filter of the program, mapped to color, and rendered as surface plots. Top and bottom colors were set to minimum and maximum signal values for each experimental protocol. Consequently, the color for the prestimulus maps "floats" to an extent, depending on these minimum and maximum values.

$\mathrm{Ca}^{2+}$ imaging. Ester loading of fura-2 into CA1 neurons followed the procedure described previously (Regehr and Tank, 1991; Connor et al., 1999). A large-bore micropipette (tip $\sim 15 \mu \mathrm{m}$ ) filled with fura-2 AM/ DMSO/Pluronic ( $10 \mu \mathrm{M}, 0.3 \%, 0.3 \%$, respectively) was positioned below the slice surface in stratum oriens, and pressure pulses $(1 \mathrm{~Hz}, 0.5$ duty cycle) were applied for 15-25 min. CA1 neurons located under the slice surface, with basal dendrites projecting to the loading site, steadily accumulated fura- 2 that diffused to cell bodies and apical dendrites. Measurements were made in the cell body layer distant from the loading site. Measurements of $\mathrm{Ca}^{2+}$ are reported as fluorescence ratios $(350 / 380 \mathrm{~nm}$ excitation) because of uncontrollable variables introduced by the loading method (Regehr and Tank, 1991; Connor et al., 1999). This bulk loading approach has the advantage that $\mathrm{Ca}^{2+}$ changes are reported from a population of healthy cells located below the slice surface, a situation analogous to that used for $\mathrm{NAD}(\mathrm{P}) \mathrm{H}$ fluorescence measurements. Image pairs $(\lambda>510 \mathrm{~nm})$ were collected for excitations at 350 and $380 \mathrm{~nm}$, background-corrected, and then ratioed. $\mathrm{Ca}^{2+}$ imaging was not contaminated by $\mathrm{NAD}(\mathrm{P}) \mathrm{H}$ fluorescence because of the relative brightness of the fura- 2 and the $510 \mathrm{~nm}$ long-pass filter, which removes most of the $\mathrm{NAD}(\mathrm{P}) \mathrm{H}$ signal.

Rhodamine 123 imaging. Slices were incubated in $26 \mu \mathrm{M}$ rhodamine 123 (Rh123) in ACSF, continuously bubbled with $95 \% \mathrm{O}_{2} / 5 \% \mathrm{CO}_{2}$ for 30 min at room temperature (Bindokas et al., 1998), and then transferred to the recording chamber where they were superfused with ACSF and warmed to $34^{\circ} \mathrm{C}$. Excitation was delivered at $510 \mathrm{~nm}$, and emission was monitored through a $610 \mathrm{~nm}$ long-pass filter. In one set of experiments simultaneous Rh123 and NAD(P)H fluorescence was measured in alternate frames of a sequence by using a single filter set (Chroma Technology) composed of a dual transmission band dichroic ( 460 and $>590 \mathrm{~nm}$, number 51002) and a dual emission filter (455 and $620 \mathrm{~nm}$, number 51003). Excitation wavelengths were switched by the Polychrome IV. This configuration yielded significantly smaller signals from each fluorophore, but the ability to make near simultaneous measurements was an effective tradeoff.

Rh123 gives an indirect measure of changes in mitochondrial inner membrane potential, $\Psi_{\mathrm{m}}$. For normal $\Psi_{\mathrm{m}}$ and the loading procedure outlined above, Rh123 is concentrated sufficiently in the mitochondria to self-quench. A reduction in $\Psi_{\mathrm{m}}$ allows leakage into the cytosol where the molecule, present in much lower concentration, fluoresces. In these preparations, over a period of $10 \mathrm{~min}$, the proton ionophore FCCP (1 $\mu \mathrm{M}$ ) produced a substantial increase in Rh123 fluorescence (peak, $80.5 \pm$ $8.2 \% ; n=6$ ), which is attributable to loss of mitochondrial inner membrane potential (see Bindokas et al., 1998). A careful comparison of the Rh123 signal with other indicators of $\Psi_{m}$ in the hippocampal slice preparation and an emphasis on the usefulness of the Rh123 signal have been published (Bindokas et al., 1998).

Stimuli. Bipolar stimulating electrodes were used for stimulation of Schaffer collateral fibers. Platinum tips ( 50 or $25 \mu \mathrm{m}$ in diameter) were placed in s. radiatum, $\sim 150 \mu \mathrm{m}$ from the pyramidal cell layer. Stimuli were delivered via a Master 8 controller, DC supply, and constant current isolation unit (A.M.P.I., Jerusalem, Israel). In those cases in which trains of stimuli were used, the stimulus frequency was $50 \mathrm{~Hz}$. Between successive tetani $5 \mathrm{~min}$ intervals were maintained. For most studies the fluorescence excitation/imaging at $3 \mathrm{~Hz}$ was begun $4 \mathrm{sec}$ before onset of the stimulus and continued for a total of $25 \mathrm{sec}$. So that the kinetics of initial $\mathrm{NAD}(\mathrm{P}) \mathrm{H}$ oxidation events (transient negative deflections) could be assessed, the acquisition rate was increased to $10-18 \mathrm{~Hz}$. In experiments to monitor the time course of recovery of $\mathrm{NAD}(\mathrm{P}) \mathrm{H}$ fluorescence changes, the acquisition rate was decreased $(0.25 \mathrm{~Hz}$ ), and longer sequences (up to $90 \mathrm{sec}$ ) were recorded.

To investigate transient responses to brief kainate (KA) exposures, we introduced a bolus of KA ( $25 \mu \mathrm{l}, 5 \mathrm{~mm}$ stock) into the perfusion line 
(continuous $2 \mathrm{ml} / \mathrm{min}$ ). The maximum peak concentration in the recording chamber was estimated at $100 \mu \mathrm{m}$ with this procedure.

For studies with local application of glutamate, glass microelectrodes were filled with $1 \mathrm{M} \mathrm{Na}$-glutamate $\left(\right.$ in $\left._{2} \mathrm{O}\right)$ and placed above the surface of the CA1 pyramidal cell layer. When filled with $1 \mathrm{M} \mathrm{KCl}$, these electrodes have a resistance of $\sim 5 \mathrm{M} \Omega$, and no evidence of glutamate leak (e.g., changes in baseline $\mathrm{NAD}(\mathrm{P}) \mathrm{H}$ fluorescence) was observed. Glutamate was ejected by passing current pulses $(20 \mu \mathrm{A}, 2 \mathrm{sec})$ at $5 \mathrm{~min}$ intervals. Comparisons were made with electrodes filled with $1 \mathrm{M} \mathrm{NaCl}$, and under these conditions identical stimuli produced no demonstrable $\mathrm{NAD}(\mathrm{P}) \mathrm{H}$ fluorescence responses.

Drugs and solutions. ACSF contained (in $\mathrm{mm}$ ): $126 \mathrm{NaCl}, 3 \mathrm{KCl}, 1.25$ $\mathrm{NaH}_{2} \mathrm{PO}_{4}, 1 \mathrm{MgSO}_{4}, 26 \mathrm{NaHCO}_{3}, 2 \mathrm{CaCl}_{2}$, and 10 glucose equilibrated with $95 \% \mathrm{O}_{2} / 5 \% \mathrm{CO}_{2}$. Cutting solution contained (in $\mathrm{mM}$ ): $3 \mathrm{KCl}, 1.25$ $\mathrm{NaH}_{2} \mathrm{PO}_{4}, 6 \mathrm{MgSO}_{4}, 26 \mathrm{NaHCO}_{3}, 0.2 \mathrm{CaCl}_{2}, 10$ glucose, 220 sucrose, and 0.43 ketamine. For zero $\mathrm{Ca}^{2+} \mathrm{ACSF}$ the $\mathrm{CaCl}_{2}$ was replaced by $\mathrm{MgSO}_{4}$, and $0.5 \mathrm{~mm}$ BAPTA $\left(\mathrm{Na}^{+}\right.$salt) was added. KA was obtained from A. G. Scientific (San Diego, CA). FCCP and CNQX were from Calbiochem, San Diego, CA). All other drugs and salts were obtained from Sigma (St. Louis, MO) and were diluted in the ACSF perfusate. FCCP was prepared as a $20 \mathrm{~mm}$ stock in ethanol. Data are presented as mean \pm SEM; significant differences between group data were evaluated by using paired or unpaired Student's $t$ tests, with $p<0.05$ considered significant.

\section{Results}

Evoked NAD $(\mathrm{P}) \mathrm{H}$ transients in murine hippocampal slices

Figure 1 illustrates basic properties of the biphasic fluorescence transients evoked by a single tetanus to Schaffer collateral inputs. The $360 \mathrm{~nm}$ light pulses (40-100 $\mathrm{msec}$ ) were used for excitation, and emission $(>410 \mathrm{~nm})$ was collected from the CA1 pyramidal cell region. The $\mathrm{GABA}_{\mathrm{A}}$ receptor antagonist bicuculline $(30 \mu \mathrm{M}$; 10 min exposure) was present in the ACSF to augment the amplitude of responses (see below). The stimulus (25 pulses, 70 $\mu \mathrm{sec}, 50 \mathrm{~Hz}$ ) was applied at the arrows and was accompanied by an immediate decrease in fluorescence. This transient decrease, hereafter referred to as the "initial component," was followed by a more sustained fluorescence increase, "overshoot" (Fig. 1A). The characteristics of the initial component are shown in more detail in Figure $1 B$, where images were acquired at $18 \mathrm{~Hz}$ in a different slice and a significant decrease in fluorescence could be detected in the second frame (i.e., within $100 \mathrm{msec}$ ) after the stimulus onset. These biphasic responses were very reproducible when tetani were spaced at sufficient intervals ( $>5 \mathrm{~min}$ ) to allow for full recovery of the overshoot between trials. Under these recording conditions the signal-to-noise ratio was sufficiently high that all traces in Figure 1 are generated from single trials. Furthermore, the response to a single shock stimulus was sufficient to generate a detectable signal. Figure $1 C$ illustrates a representative of six experiments in which the number of stimuli in a volley was decreased from 25 to 1 . A progressive decrease in both components of the response can be seen, but both components of responses were still evident with the single shock. The sensitivity of detection could be increased further for very weak presynaptic stimuli by averaging responses to multiple trials generated at 1-3 min intervals (data not shown). However, single trials proved suitable for all subsequent experiments in this study.

Both components of the fluorescence responses evoked by electrical stimuli were abolished by exposure to tetrodotoxin (1 $\mu \mathrm{M} ; n=6$ ) or by a combination of ionotropic glutamate receptor antagonists. Figure $1 D$ shows representative traces from a single slice before and after $10 \mathrm{~min}$ of perfusion with a combination of CNQX $(50 \mu \mathrm{M})$ and APV $(100 \mu \mathrm{M})$. From four such experiments the amplitude of the initial component was decreased from $-3.50 \pm 0.64 \%$ to an isochronal value of $-0.28 \pm 0.07 \%(p<$ 0.02 ), and the mean overshoot of $4.84 \pm 1.63 \%$ was abolished
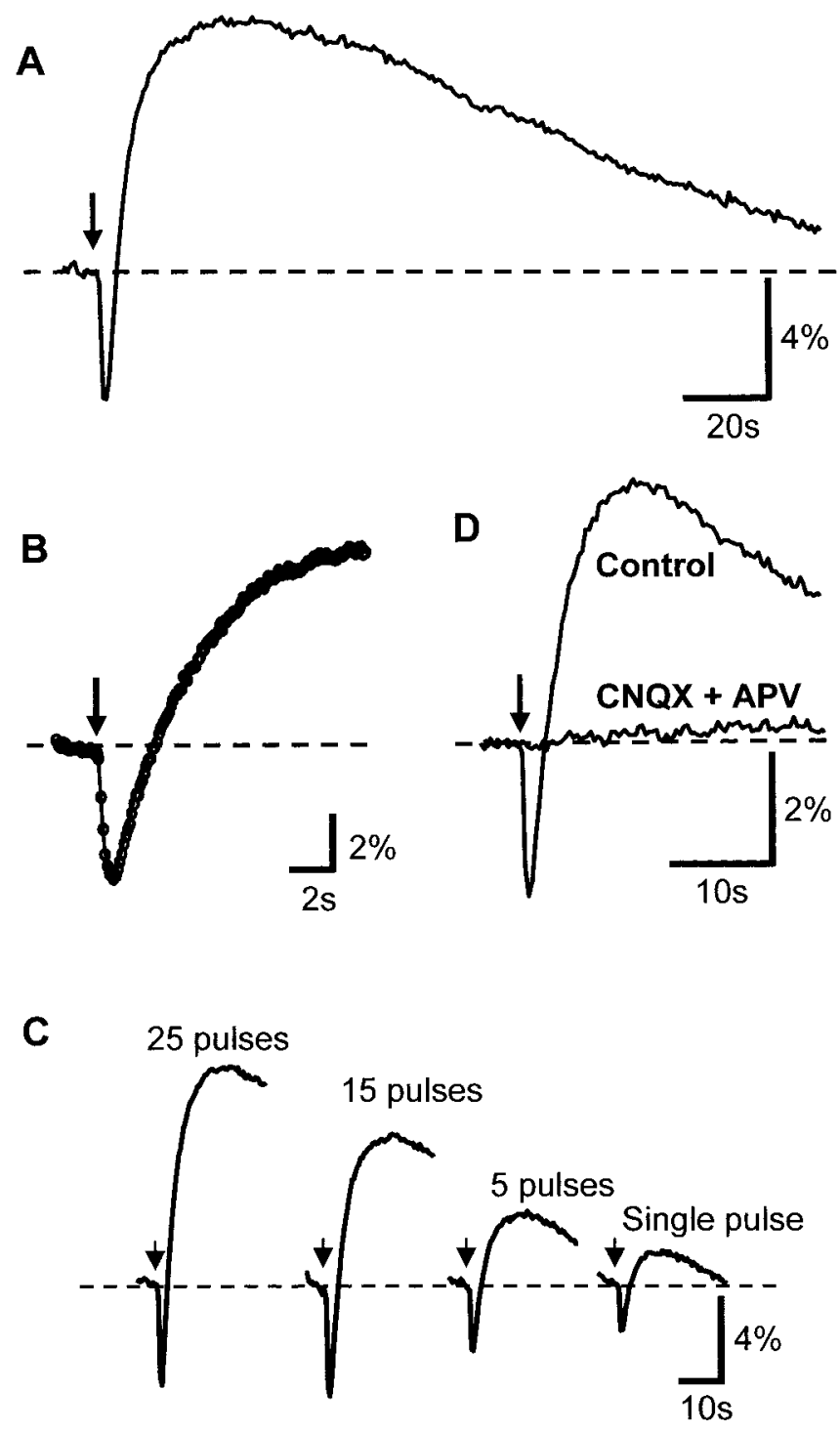

Figure 1. Temporal characteristics of $\mathrm{NAD}(\mathrm{P}) \mathrm{H}$ fluorescence changes evoked by electrical stimuli applied to s. radiatum. In all panels the stimuli were applied at the arrow; NAD(P)H fluorescence was monitored in s. pyramidale and expressed as $\Delta F / F_{0}$. Bicuculline $(30 \mu \mathrm{M})$ was present in all cases; data shown are from single trials. $A$, Response to single tetanus ( 25 pulses, $50 \mathrm{~Hz}$ ) illustrating the characteristic biphasic NAD(P)H response, comprising an initial NAD(P)H fluorescence decrease (oxidation) followed by a more sustained $N A D(P) H$ fluorescence increase (reduction). Acquisition rate, $3 \mathrm{~Hz}$. $B$, The onset of the response is shown in more detail in a trial in which the acquisition rate was increased to $18 \mathrm{~Hz}$ (stimulus, 25 pulses, $50 \mathrm{~Hz}$ ). The onset of the response was detected within 100 msec of stimulus onset. C, NAD(P)H transients could be resolved in single trials after more modest presynaptic stimuli. Panels illustrate successive trials ( 3 min intervals) in which the number of pulses in the stimulus train was decreased from 25 to a single shock. D, Both components of $\mathrm{NAD}(\mathrm{P}) \mathrm{H}$ responses were blocked by a combination of ionotropic glutamate receptor antagonists. Representative trials illustrate responses in normal ACSF and after $10 \mathrm{~min}$ exposure to $50 \mu \mathrm{m}$ CNQX and $100 \mu \mathrm{m}$ APV.

$(-0.22 \pm 0.20 \%)$. The effective block of evoked transients with this antagonist combination suggests that the signals depend primarily on postsynaptic neuronal activation rather than on presynaptic excitation and/or neuron/glial glutamate uptake. The wavelengths used to excite and measure fluorescence were those commonly used in $\mathrm{NAD}(\mathrm{P}) \mathrm{H}$ measurements, and the biphasic nature of the signal has been shown in photo multiplier measurements from isolated neurons (Duchen, 1992) and rat hippocampal slices (Schuchmann et al., 1999; Kovacs et al., 2001). Consequently, the more generic terminology, "fluorescence change," 
will be replaced with "NAD(P)H transients." A more detailed characterization of the intracellular events driving these changes is deferred until after the next section.

To establish where evoked $\mathrm{NAD}(\mathrm{P}) \mathrm{H}$ transients lie with respect to maximally reduced and maximally oxidized $\mathrm{NAD}(\mathrm{P}) \mathrm{H}$ signals, we examined responses to rotenone and FCCP. Rotenone $(5 \mu \mathrm{M})$ produced a progressive, very large fluorescence increase (30.7 $\pm 3.9 \%$ at $15 \mathrm{~min}, n=8 ; 70.2 \pm 9.8 \%$ at $40 \mathrm{~min}, n=3$ ) as would be expected as a consequence of block of complex I and decrease in NADH consumption. FCCP produced a transient fluorescence increase ( $15.1 \pm 5.4 \%$ for $1 \mu \mathrm{M}, n=4 ; 28.6 \pm 1.6 \%$ for $5 \mu \mathrm{M}, n=8$ ) that peaked $6-8 \mathrm{~min}$ after the onset of FCCP exposure. After the peak increase $\mathrm{NAD}(\mathrm{P}) \mathrm{H}$ levels then began a very large progressive decrease $(47.7 \pm 1.2 \% ; n=5)$ after $40 \mathrm{~min}$ of $5 \mu \mathrm{M}$ FCCP exposure. Thus the extremes observed with rotenone and FCCP are substantially larger than the evoked signals discussed above, implying that the amplitudes of signals evoked by electrical stimulation were not limited by maximal changes to reduction and oxidation of the $\mathrm{NAD}(\mathrm{P}) \mathrm{H} / \mathrm{NAD}(\mathrm{P})$ pool. The mechanism(s) underlying the transient $\mathrm{NAD}(\mathrm{P}) \mathrm{H}$ increase, seen early during FCCP exposure in these slice preparations, currently is(are) unknown. However, to ensure that fluorescence signals observed with rotenone and FCCP were indeed a consequence of mitochondrial function perturbations, we compared $\mathrm{NAD}(\mathrm{P}) \mathrm{H}$ fluorescence signals with fluorescence signals attributable to FAD (see Materials and Methods). In these separate series of experiments near-simultaneous $\mathrm{NAD}(\mathrm{P}) \mathrm{H} / \mathrm{FAD}$ measurements were made by alternating appropriate filter sets during drug exposure. As would be expected, $\mathrm{NAD}(\mathrm{P}) \mathrm{H}$ increases produced by rotenone over $15 \mathrm{~min}(29.9 \pm 2.9 \%)$ were mirrored by decreases in FAD fluorescence $(25.7 \pm 2.5 \% ; n=5)$. Likewise, initial transient $\mathrm{NAD}(\mathrm{P}) \mathrm{H}$ increases produced by FCCP $(5 \mu \mathrm{M})$ were mirrored by FAD decreases $(29.3 \pm 2.5 \% \mathrm{NAD}(\mathrm{P}) \mathrm{H}$ increase vs $27.1 \pm 2.0 \%$ FAD decrease; $n=3$ each).

\section{Spatially resolved $\mathrm{NAD}(\mathrm{P}) \mathrm{H}$ signals}

The $\mathrm{NAD}(\mathrm{P}) \mathrm{H}$ signal tracked electrical activity with a high degree of spatial resolution. This is illustrated first for Schaffer collateral stimulation in Figure 2, which shows maps of optical signals at the peak of the initial component (500 msec after stimulus onset) and the overshoot (10 sec after stimulus). Figure $2 \mathrm{~A}$ shows the peak optical signals elicited by a stimulus of five $1 \mathrm{~mA}$ pulses delivered at $50 \mathrm{~Hz}$. The position of the stimulus electrode in s. radiatum is indicated on the bright-field image of the slice (Fig. $2 E$ ). The optical changes were limited to an $\sim 150 \mu \mathrm{m}^{2}$ area near the stimulus electrode, centered in the s. radiatum. This corresponds to the area that should receive the highest density of inputs from the activated presynaptic fibers. In Figure $1 B$ the stimulus intensity was increased to $2 \mathrm{~mA}$. Peak magnitudes of both the initial component and the overshoot were increased, as was the spatial spread of the signal. Near the electrode significant changes became detectable in s. pyramidale and s. oriens. The slice then was disinhibited by the addition of bicuculline $(30 \mu \mathrm{M})$. This treatment resulted in higher efficiency of excitatory stimuli because the time course of the GABA $A_{A}$ IPSP somewhat overlaps the EPSP and persists long enough to summate and shunt subsequent EPSPs evoked by a high-frequency stimulus train (Grinvald et al., 1982). Figure $2 C$ illustrates the peak optical signals evoked by the $2 \mathrm{~mA}$ stimulus train after a 2 min exposure to bicuculline. Visualized with the $\mathrm{NAD}(\mathrm{P}) \mathrm{H}$ signal, the excitation was seen to spread further from the stimulus electrode along the beam of stimulated collateral fibers. Additionally, there were now even larger optical signals detected in s. pyramidale and s. oriens.

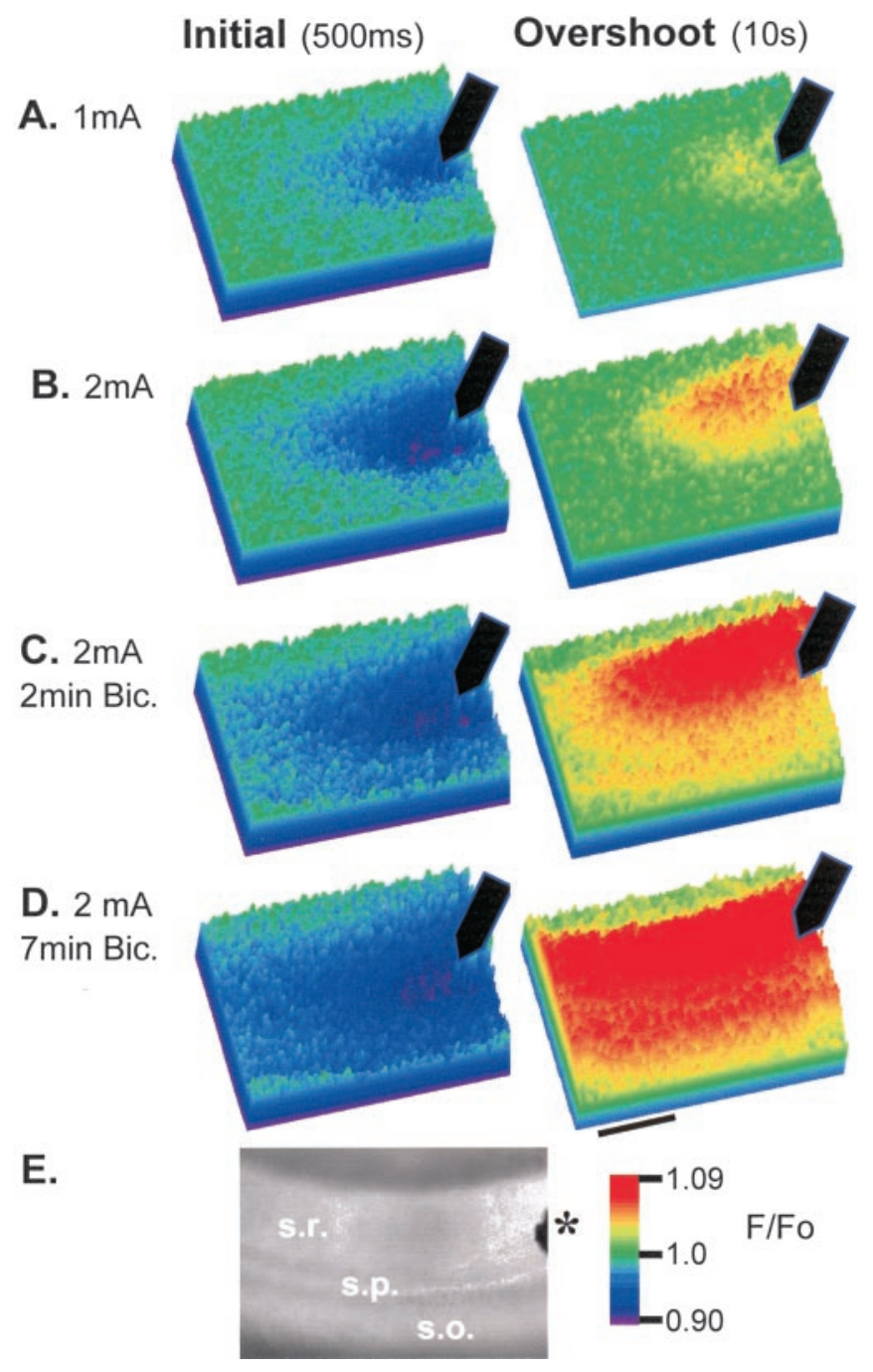

Figure 2. Spatial characteristics of $\mathrm{NAD}(\mathrm{P}) \mathrm{H}$ transients evoked by stimulation in s. radiatum. Color panels $A-D$ illustrate $N A D(P) H$ fluorescence changes at times corresponding to the peak initial component and overshoot ( $500 \mathrm{msec}$ and 10 sec after stimulus onset, respectively). Scale $\mathrm{bar}, 200 \mu \mathrm{m}$. Filled arrows indicate the position of the stimulating electrode. $A$, The peak optical signals elicited by a stimulus of five $1 \mathrm{~mA}$ pulses at $50 \mathrm{~Hz}$. The optical changes were limited to an $\sim 150 \mu \mathrm{m}$ area near the stimulus electrode, centered in s. radiatum. Increasing the stimulus intensity $(B ; 2 \mathrm{~mA})$ increased the magnitudes of both the initial component and the overshoot and increased the spatial spread of the signal. Near the electrode significant changes became detectable in s. pyramidal and s. oriens. C, Two minute bicuculline exposure. The plume of excitation can be seen to spread further from the stimulus electrode along s. radiatum. Additionally, there are now even larger optical signals detected in s. pyramidal and s. oriens. D, Seven minute bicuculline exposure. The $2 \mathrm{~mA}$ stimulus train now triggers large biphasic optical signals in the entire CA1 field within view. E, Bright-field image of the slice showing the position of the stimulating electrode (asterisk) together with the locations of s. oriens (so), s. pyramidale (sp), and s. radiatum (sr).

These observations are consistent with supra-threshold excitation near the electrode and more efficient excitation by the lower density of activated fibers more distant from the electrode. After a longer exposure to bicuculline ( $7 \mathrm{~min}$ ), which should allow for more effective infiltration of the antagonist, the slices tended to become even more excitable, a condition illustrated in Figure $2 D$, in which the $2 \mathrm{~mA}$ stimulus train now triggered large, biphasic optical signals in the entire CA1 field within view. $\mathrm{GABA}_{\mathrm{A}}$ receptor antagonism always produced an increase in signal magnitude as well as the activated area. Figure 3 shows the mean effects of both increasing stimulus strength and bicuculline addition on a 
A
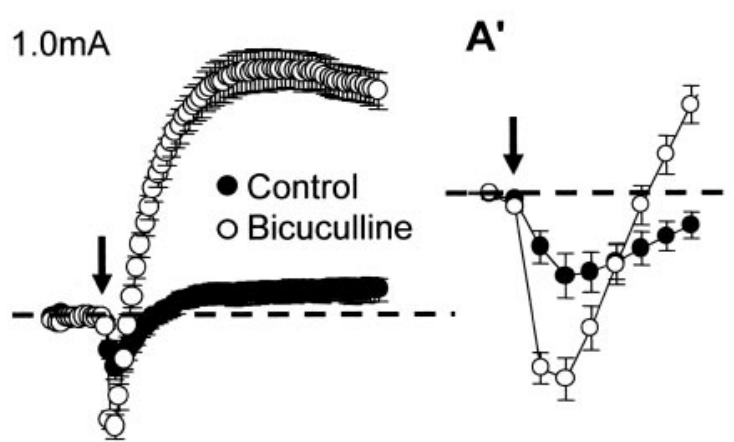

B

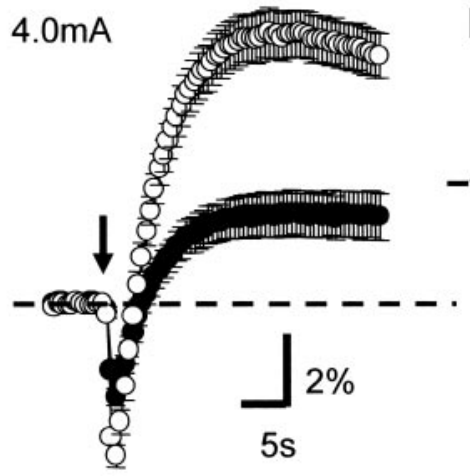

B'

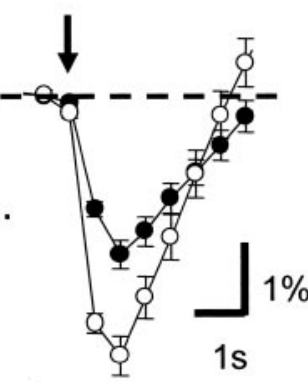

C

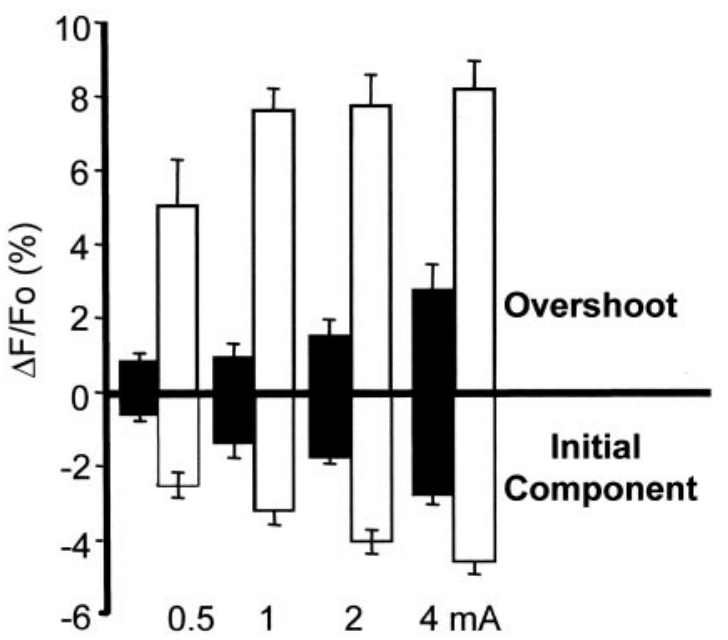

Figure 3. Increase in $N A D(P) H$ responses by disinhibition. $A, B$, Mean biphasic responses to tetani applied at two different stimulus intensities (1 and $4 \mathrm{~mA}$ ). Control responses are represented by filled circles, and responses in the same preparations after 10 min of bicuculline exposure ( $30 \mathrm{~mm}$ ) are in open circles. Arrows indicate stimulus train $(25 \mathrm{pulses}, 50 \mathrm{~Hz}) . A^{\prime}, B^{\prime}$, Initial components of responses shown in $A$ and $B$ at an expanded time base. $C$, Summary of effects on initial and overshoot responses for a range of stimulus intensities. Filled bars represent control responses, and open bars represent bicuculline. Note the large effect on overshoot responses as compared with the more modest increase of initial components. For all panels the data are the mean $\pm \mathrm{SEM} ; n=6$.

group of six slices from six animals. All stimuli in normal ACSF evoked initial components and overshoots of similar magnitude, and both components increased monotonically with increasing stimulus intensity (Fig. $3 A, B$, open circles; $C$, open bars). In bicuculline both components were larger for a given stimulus strength. The overshoot was disproportionately larger and showed a steep dependence on stimulus amplitude, being nearly maximal at $1 \mathrm{~mA}$ when $\mathrm{GABA}_{\mathrm{A}}$ receptors were blocked.

Figure $3, A^{\prime}$ and $B^{\prime}$, show responses to 1 and $4 \mathrm{~mA}$ stimuli at an
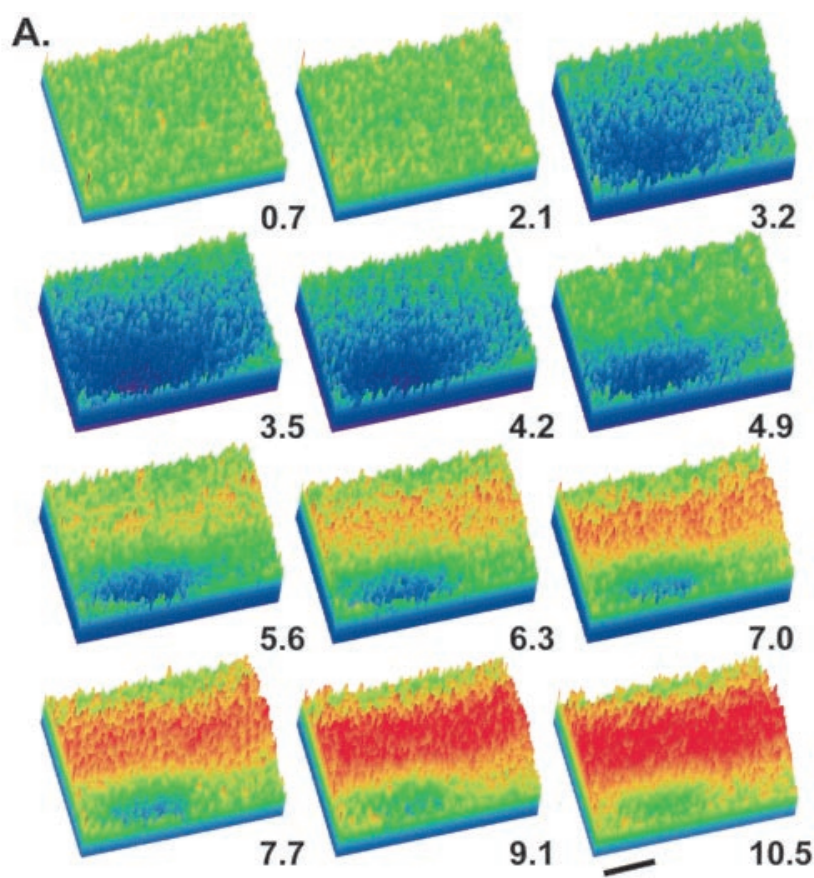

B.

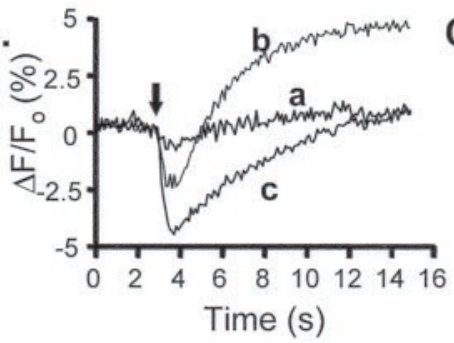

C.

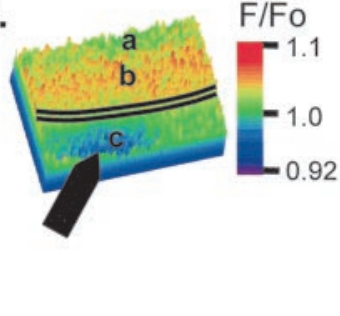

Figure 4. Alveus stimulation. A bipolar stimulating electrode was used to deliver a single tetanus (10 pulses, $50 \mathrm{~Hz}$ ); NAD(P)H fluorescence changes were imaged at $10 \mathrm{~Hz}$. A, Selected frames at $700 \mathrm{msec}$ intervals illustrating a clear spatial difference between the peak initial component and overshoot. Times are indicated in seconds; stimulus onset occurs at $3 \mathrm{sec}$. The initial component was largest in s. oriens, centered above the stimulus electrode; in s. pyramidale and s. radiatum it was smaller and showed a wider lateral extent. A wide spatial divergence in the responses of the two components developed, beginning 1-2 sec after the stimulus. The initial component remained in the same localized area in s. oriens while a strong overshoot developed in s. pyramidale and s radiatum. This overshoot clearly covers the lateral extent of the field. Scale bar, $200 \mu \mathrm{m}$. B, Data from the same trial extracted from the three locations indicated in C. Arrow indicates onset of stimulus train. There is no significant change in fluorescence at location a, almost no overshoot at location c, and a biphasic change in location b. C, Single frame illustrates the location of the pyramidal cell layer (black lines) and stimulating electrode (filled arrow).

expanded time scale so that the rate of rise of both components of evoked $\mathrm{NAD}(\mathrm{P}) \mathrm{H}$ transients can be observed in more detail. Bicuculline exposure significantly increased the peak rate of rise of both components of evoked $\mathrm{NAD}(\mathrm{P}) \mathrm{H}$ transients (i.e., $2.20 \mathrm{vs}$ $0.40 \% / \mathrm{sec}$ for $1 \mathrm{~mA}$ and $2.34 \mathrm{vs} 1.1 \% / \mathrm{sec}$ for $4 \mathrm{~mA} ; n=6)$. This large difference raised the possibility that the more rapid development of a large overshoot response could mask the full extent of the initial component. The next series of experiments, in which the stimulating electrode was placed in the alveus, lends support to this suggestion.

Alveus stimulation also produced a spatially restricted $\mathrm{NAD}(\mathrm{P}) \mathrm{H}$ response but with different dynamic characteristics when compared with s. radiatum stimulation. Figure 4 illustrates the time course of the optical signal after a single stimulus train of 10 pulses ( $1 \mathrm{~mA}, 50 \mathrm{~Hz}$ in the presence of bicuculline). The initial component was largest in s. oriens, centered above the stimulus 
electrode. In s. pyramidale and s. radiatum the initial component was smaller and showed a wider lateral extent. A wide divergence in the two components of the $\mathrm{NAD}(\mathrm{P}) \mathrm{H}$ transient developed, beginning 1-2 sec after the stimulus. The negative-going initial component remained in the same localized area in s. oriens, whereas a strong overshoot developed in s. pyramidale and s. radiatum. This overshoot clearly covered the lateral extent of the field. Thus unlike the situation with s. radiatum stimulation (Fig. 2 ), stimulation in alveus resulted in clear spatial mismatch between the two components of $\mathrm{NAD}(\mathrm{P}) \mathrm{H}$ transients (Fig. 4). These data (Fig. $4 B$ ) suggest that the initial NAD (P)H decrease in fact is longer-lasting in the alveus, because it is not masked by the emergence of a large overshoot response in this location.

Responses to alveus stimulation were blocked in their entirety by CNQX/APV or by TTX $(n=4)$, implying that, like responses to Schaffer collateral stimulation, they are a direct consequence of postsynaptic activation of ionotropic glutamate receptors. The broad lateral spread is consistent with orthodromic and antidromic activation of glutamatergic fibers in the s. radiatum beam by branches that course from s. oriens (Swanson et al., 1989). The glutamate blocker effect also implies that activated cholinergic and other pathways known to course through the alveus (Swanson et al., 1989) do not give rise directly to the optical signals. This is not to exclude secondary, cooperative effects of these pathways, such as the increased dendritic excitability after activation of cholinergic inputs (Müller and Connor, 1991). We do not have a hypothesis regarding why s. oriens shows such a small relative overshoot under this stimulation condition; however, we found that glutamate iontophoresis onto the pyramidal cell layer also resulted in the largest initial $\mathrm{NAD}(\mathrm{P}) \mathrm{H}$ decreases in the s. oriens, with large overshoots occurring in s. radiatum (see Fig. 6 below). This suggests that there are regional differences that result in a larger overshoot in different locations regardless of stimulus modality. The finding that the compound $\mathrm{NAD}(\mathrm{P}) \mathrm{H}$ responses do not reflect an obligatory coupling between the two components points to a significant advantage of these imaging measurements (when compared with PMT-based approaches), because if data were integrated over a large area, the full extent of each component could be underestimated significantly in some cases.

\section{Intracellular pathways driving $\mathrm{NAD}(\mathrm{P}) \mathrm{H}$ transients}

Figure 5, $A$ and $B$, compares $\mathrm{NAD}(\mathrm{P}) \mathrm{H}$ fluorescence signals with fluorescence signals attributable to FAD. In these studies brief stimulus trains ( $2 \mathrm{~mA}, 10$ pulses) were applied to s. radiatum at 5 min intervals. Filter sets were changed between each stimulus so that $\mathrm{NAD}(\mathrm{P}) \mathrm{H}$ and FAD transients were compared in each of five slices. As would be expected if these signals are indeed reflective of demands on oxidative phosphorylation and TCA cycle activity, the FAD signal is inverted when compared with the $\mathrm{NAD}(\mathrm{P}) \mathrm{H}$ transient (Fig. 5A,B). In all other respects the FAD signal is very similar to the $\mathrm{NAD}(\mathrm{P}) \mathrm{H}$ signal, with the initial transient components of both signals peaking at the same time and both being followed by more long-lasting overshoot components. This inverse but temporally matched relationship is also important in establishing that light-scattering changes play little or no part in the measurements. If signals were attributable to light-scattering changes (Salzberg et al., 1985; MacVicar and Hochman, 1991), transients with identical (not inverted) polarity would be expected with two wavelengths separated by only $\sim 130 \mathrm{~nm}$.

Figure $5 C$ shows that the initial component of either the $\mathrm{NAD}(\mathrm{P}) \mathrm{H}$ or FAD fluorescence signal is coincident with increases in neuronal intracellular $\mathrm{Ca}^{2+}$ concentration. These measurements were made in slices in which CA1 pyramidal neurons

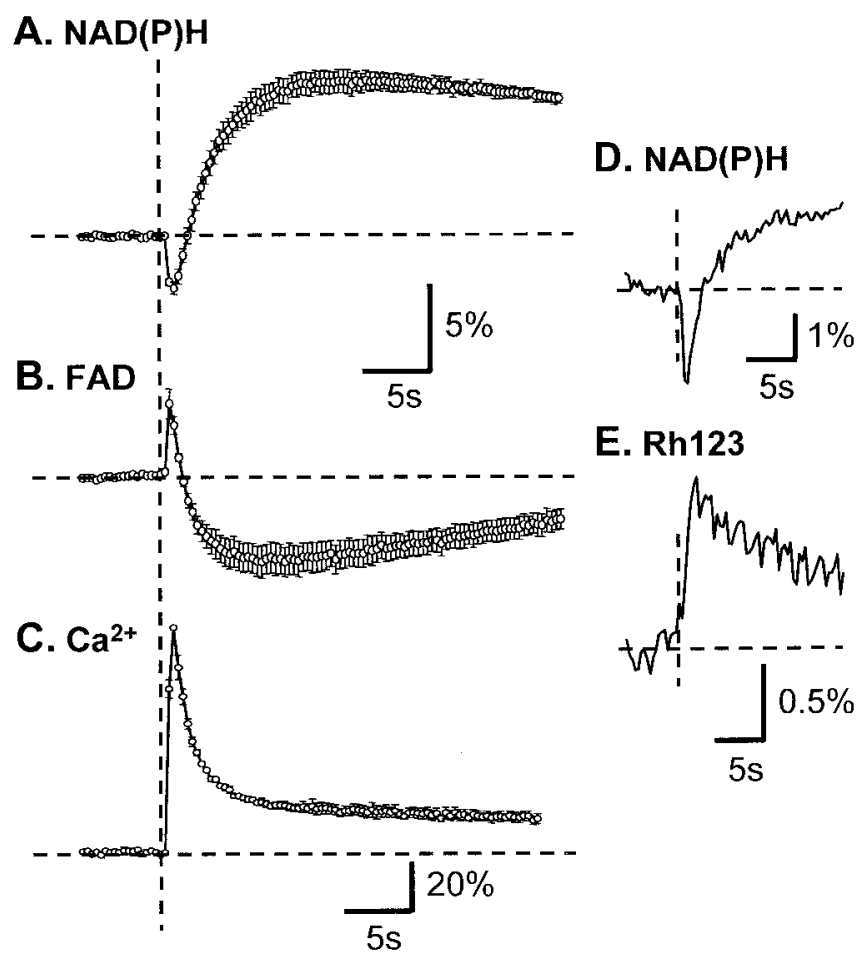

Figure 5. Comparison of $\mathrm{NAD}(\mathrm{P}) \mathrm{H}$ fluorescence transients with other fluorescence signals. Stimuli in all panels were single tetani applied to s. radiatum ( 10 pulses, $50 \mathrm{~Hz}$ ) in the presence of bicuculline. $A, B$, Endogenous FAD fluorescence signals are inverted as compared with $\mathrm{NAD}(\mathrm{P}) \mathrm{H}$ transients. Stimuli were maintained at $5 \mathrm{~min}$ intervals, and imaging alternated between the two imaging modalities in each slice. Values are $\Delta F / F_{0}$, mean $\pm S E M ; n=5$. C, $\mathrm{Ca}^{2+}$ transients peak at similar times to initial NAD(P)H oxidation. Fura-2 ratios were normalized against the peak response in each preparation (mean $\pm \mathrm{SEM} ; n=4$ ). To allow for direct comparison of the three signals, we obtained the data in $A-C$ with identical stimuli and acquisition settings; the stimuli were aligned at the vertical dashed line. D, E, Simultaneous imaging of $\mathrm{NAD}(\mathrm{P}) \mathrm{H}$ and Rh123 fluorescence transients, with the stimulus applied at the vertical dashed line. This is a single trial and illustrates that the Rh123 fluorescence increase is coincident with the initial NAD(P)H fluorescence decrease. In all panels the data were acquired at $3 \mathrm{~Hz}$.

were loaded by using fura-2 AM (see Materials and Methods). The stimuli and time points of image acquisition are identical to those used in Figure 5, $A$ and $B$, so that the kinetics of the three signals can be compared directly. The stimulus trains produced robust $\mathrm{Ca}^{2+}$ transients, with an initial peak that was coincident with the initial decrease in $\mathrm{NAD}(\mathrm{P}) \mathrm{H}$ fluorescence and increase in FAD fluorescence. This strong correlation is consistent with the hypothesis that neuronal $\mathrm{Ca}^{2+}$ increases underlie $\mathrm{NAD}(\mathrm{P}) \mathrm{H}$ fluorescence transients (Duchen, 1992; Schuchmann et al., 2001). However, it remains possible from these data that $\mathrm{Ca}^{2+}$ and $\mathrm{NAD}(\mathrm{P}) \mathrm{H}$ signals are not related causally but, rather, may be parallel responses triggered independently by neuronal membrane depolarization. Evidence supporting the latter possibility is discussed in the next section.

As would be expected from the large $\mathrm{Ca}^{2+}$ transients that were evoked, these stimuli also were accompanied by a loss of mitochondrial potential $\left(\Psi_{\mathrm{m}}\right)$ as measured from experiments run in parallel on slices loaded with Rh123 (Duchen et al., 1993; McCormack and Denton., 1993; Loew et al., 1994; White and Reynolds, 1997; Bindokas et al., 1998; Schuchmann et al., 2000). Increases in Rh123 fluorescence are an indicator of decreases in $\Psi_{\mathrm{m}}$ (see Materials and Methods) (Bindokas et al., 1998). An example of simultaneous $\mathrm{NAD}(\mathrm{P}) \mathrm{H}$ and Rh123 fluorescence measurements is given in Figure 5, $D$ and $E$, and shows that the $\Psi_{\mathrm{m}}$ decrease occurred coincidentally with the initial component of the 
$\mathrm{NAD}(\mathrm{P}) \mathrm{H}$ response. These data also would be consistent with a causal role of mitochondrial $\mathrm{Ca}^{2+}$ accumulation in the generation of $\mathrm{NAD}(\mathrm{P}) \mathrm{H}$ transients in slice, but more direct evidence would require experiments that tested the removal of extracellular $\mathrm{Ca}^{2+}$ on these responses.

\section{Are intracellular $\mathrm{Ca}^{2+}$ increases required for $\mathrm{NAD}(\mathrm{P}) \mathrm{H}$ transients in slice?}

Studies in a range of cell types have shown that mitochondrial $\mathrm{Ca}^{2+}$ increases can regulate mitochondrial NADH levels (Pralong et al., 1992; Duchen et al., 1993; McCormack and Denton, 1993; Hajnoczky et al., 1995; Rohacs et al., 1997; Brandes and Bers, 1999; Pitter et al., 2002; Voronina et al., 2002). In brain slices the initial $\mathrm{NAD}(\mathrm{P}) \mathrm{H}$ decreases have been attributed to mitochondrial $\mathrm{Ca}^{2+}$ accumulation and ROS production and subsequent increases to $\mathrm{Ca}^{2+}$-dependent stimulation of the TCA cycle (Kovacs et al., 2001; Schuchmann et al., 2001); however, this proposal has not been tested directly.

Although synaptic activation offers the tightest time resolution of stimulus delivery, it is not possible to test the requirement of extracellular $\mathrm{Ca}^{2+}$ with this stimulus protocol, because complete removal of extracellular $\mathrm{Ca}^{2+}$ prevents neurotransmitter release. Therefore, we examined the effects of extracellular $\mathrm{Ca}^{2+}$ removal on responses to exogenous application of the agonists glutamate or kainate. Figure $6 A$ shows maps of $\mathrm{NAD}(\mathrm{P}) \mathrm{H}$ transients produced by $2 \mathrm{sec}$ glutamate pulses $(20 \mu \mathrm{A})$ applied by iontophoresis from a micropipette positioned above the pyramidal cell layer (see Materials and Methods). As with responses evoked by presynaptic stimulation (see above), glutamateevoked responses were biphasic, with an initial decrease followed by a longer-lasting overshoot. The duration of the initial component was significantly longer than that observed with the Schaffer collateral stimuli, presumably as a consequence of the longer stimulus duration ( 2 sec compared with $0.1-0.5$ sec for electrical stimulus trains) as well as the time taken for the agonist to diffuse to sites of action within the slice. The overshoot in s. radiatum was much more prominent than in s. oriens, as was the case for electrical stimulation of the alveus (see Fig. 4 above). The responses to iontophoresis were a consequence of glutamate delivery rather than any direct effect of the iontophoresis current, because no $\mathrm{NAD}(\mathrm{P}) \mathrm{H}$ responses were evoked when current polarity was reversed $(n=6)$ or when iontophoresis electrodes were filled with $\mathrm{NaCl}(1 \mathrm{M})$ rather than with glutamate $(n=5$; Fig. $6 E)$. Both phases of the response to glutamate were blocked by a combination of CNQX $(50 \mu \mathrm{M})$ and APV $(100 \mu \mathrm{M})(n=3)$. Figure 7 compares the time courses of $\mathrm{NAD}(\mathrm{P}) \mathrm{H}$ signals with $\mathrm{Ca}^{2+}$ and Rh123 transients to $2 \mathrm{sec}$ glutamate pulses $(20 \mu \mathrm{A})$ applied from micropipettes positioned above the pyramidal cell layer. The acquisition parameters were matched to allow for direct comparison of the three signals. $\mathrm{Ca}^{2+}$ and $\mathrm{Rh} 123$ fluorescence signals were monophasic transient increases, as would be expected as a consequence of $\Psi_{\mathrm{m}}$ depolarization (Duchen et al., 1993; McCormack and Denton, 1993; Loew et al., 1994; White and Reynolds, 1997; Bindokas et al., 1998; Schuchmann et al., 2000), and the maximum rate of increase for both signals correlated with the initial decrease of $\mathrm{NAD}(\mathrm{P}) \mathrm{H}$ signals (Fig. 7A-C). These time relationships were qualitatively similar as described above for synaptic stimulation, suggesting that mechanisms underlying responses to these pulses of exogenous glutamate may be extended to glutamate that is released after electrical stimulation of presynaptic inputs.

After glutamate iontophoresis the overshoot component recovered fully within $2 \mathrm{~min}$; therefore, for subsequent studies 5
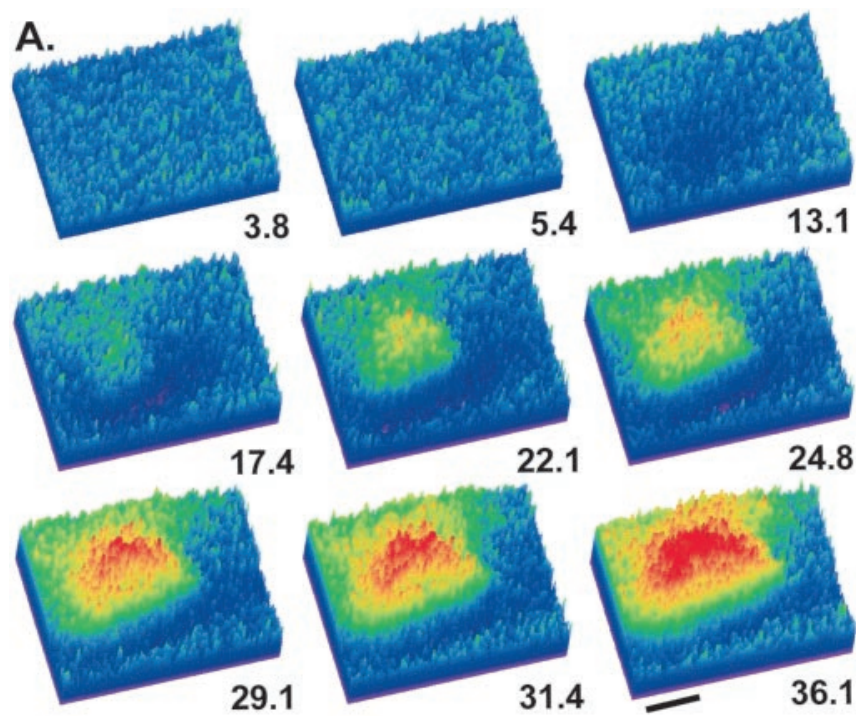

B.

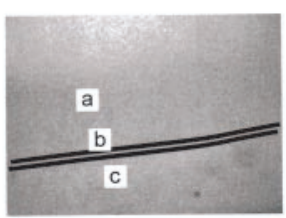

c.

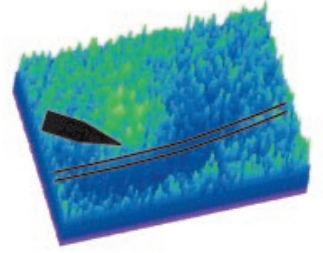

D.

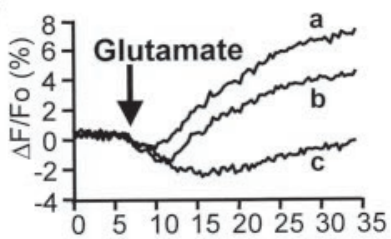

E.

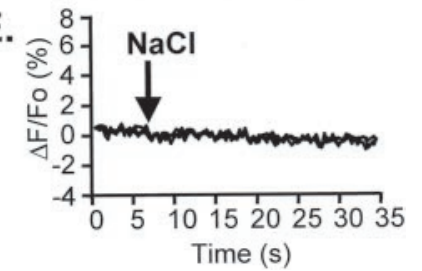

Figure 6. $N A D(P) H$ responses evoked by iontophoretic application of glutamate ( $20 \mu \mathrm{A}, 2$ $\mathrm{sec})$. A, Pseudocolor images show changes in NAD(P)H fluorescence. Images were acquired at 3 $\mathrm{Hz}$, and selected frames are shown at the times indicated in seconds. The stimulus was applied at $t=6.7 \mathrm{sec}$. Note the different spatial distributions of the NAD(P)H decrease and overshoot. Scale bar, $200 \mu \mathrm{m}$. B, Baseline NAD(P)H fluorescence in the same field, demonstrating that resting levels are relatively uniform over the region of interest. Pyramidal cell layer is indicated by black lines. $C$, Single frame indicating the position of the glutamate microelectrode (black arrow). D, Data extracted from the three regions (a-c), indicated in B.E, Control for iontophoresis current demonstrating that replacement of glutamate with $\mathrm{NaCl}$ produces no discernible $\mathrm{NAD}(\mathrm{P}) \mathrm{H}$ transient with identical stimulus current.

min intervals were maintained between successive stimuli. Figure $7 A$ shows that, despite the full recovery in $\mathrm{NAD}(\mathrm{P}) \mathrm{H}$ signal, repeated stimuli led to a progressive decline in the amplitude of overshoot responses evoked by glutamate iontophoresis. Interestingly, amplitudes of the initial components responses did not decline but showed a trend toward an increase in amplitude with repetitive trials (Fig. $7 A$, open bars). There was no significant change in the value of resting $\mathrm{NAD}(\mathrm{P}) \mathrm{H}$ fluorescence measured immediately before each of the trials (mean fluorescence intensity, 117.2 \pm 4.9 vs $119.4 \pm 5.8$ before first and third trial, respectively; $n=6$ ). Fura-2 signals and Rh123 signals were not decreased during the same repetitive glutamate exposures (Fig. $7 B, C$, open bars). Based on the results above, one possible explanation for the disparate effects of repetitive stimulation on the two components is that the two components are independent events and that the onset of the overshoot response normally masks the full amplitude of the initial $\mathrm{NAD}(\mathrm{P}) \mathrm{H}$ decrease.

After the establishment of three glutamate responses in con- 

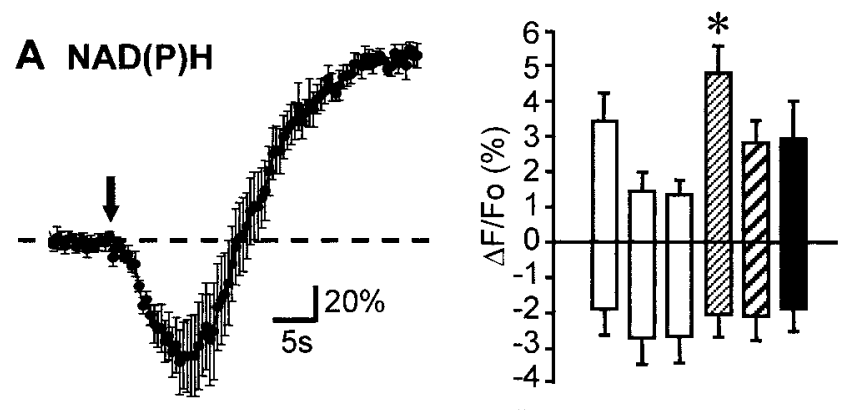

B Fura-2
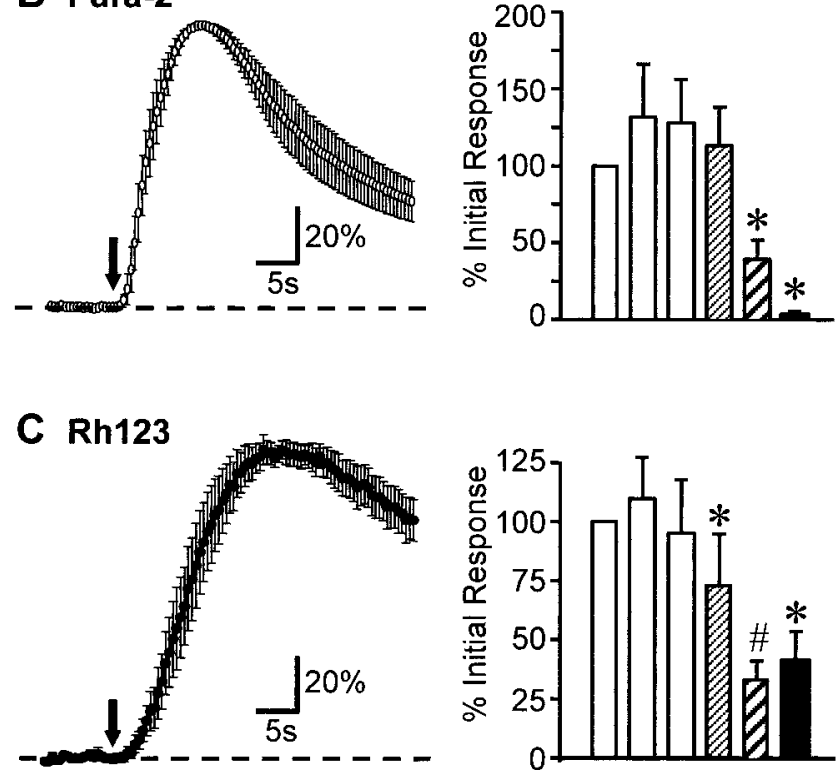

Figure 7. Inhibition of $\mathrm{Ca}^{2+}$ influx did not reduce $\mathrm{NAD}(\mathrm{P}) \mathrm{H}$ transients. For these experiments the stimulus was glutamate applied via microiontophoresis ( $20 \mu \mathrm{A}, 2$ sec; arrows). Left panels show that in regular ACSF the glutamate stimuli produced biphasic NAD(P)H fluorescence transients and monophasic fura- 2 and $\mathrm{Rh} 123$ fluorescence increases $(A-C ; n=6,5,7$, respectively). To allow for direct comparison of the three signals, we obtained the data in $A-C$ with identical stimulus and acquisition settings. The initial undershoot was coincident with the rising phase of intracellular $\mathrm{Ca}^{2+}$ increase and with the rising phase of the $\mathrm{Rh} 123$ signal. Data in left panels are normalized against peak responses. Right panels plot the effect of the removal of extracellular $\mathrm{Ca}^{2+}$ on these three fluorescence signals (mean $\pm \mathrm{SEM}$ ). Three glutamate trials in regular ACSF (open bars) were followed by three trials in $\mathrm{Ca}^{2+}$-free ACSF/0.5 mM BAPTA (hatched and filled bars; see Materials and Methods). NAD(P)H fluorescence transients were increased consistently 2 min after beginning zero $\mathrm{Ca}^{2+}$ perfusion $\left({ }^{*} p<0.03\right)$; even after 12 min of $\mathrm{Ca}^{2+}$ removal both components were not significantly different from responses in control $\operatorname{ACSF}(A$, right; $n=6)$. Confirming the effective removal of extracellular $\mathrm{Ca}^{2+}$ from the slice, fura-2 signals virtually were abolished by perfusion with zero $C \mathrm{C}^{2+} / \mathrm{BAPTA}\left(B\right.$, right; $^{*} p<$ $0.02)$. Rh123 fluorescence transients were reduced significantly in zero $\mathrm{Ca}^{2+}$ conditions $\left({ }^{*} p<\right.$ $0.04 ; \# p<0.02$ ).

trol ACSF, three identical responses were evoked in zero $\mathrm{Ca}^{2+} /$ ACSF supplemented with $0.5 \mathrm{~mm}$ BAPTA (see Materials and Methods). Between all stimuli 5 min intervals were maintained. We were surprised to find that, in the first trial in zero $\mathrm{Ca}^{2+}(2$ min exposure), the overshoot component of glutamate-evoked $\mathrm{NAD}(\mathrm{P}) \mathrm{H}$ transients was consistently, significantly increased $(p<0.03)$. With the second and third trials in zero $\mathrm{Ca}^{2+}$ the overshoot was smaller, but still equal to or greater, than values obtained in normal ACSF. In all three trials in zero $\mathrm{Ca}^{2+} / \mathrm{ACSF}$ the amplitude of the initial component was not significantly different from values in control ACSF.
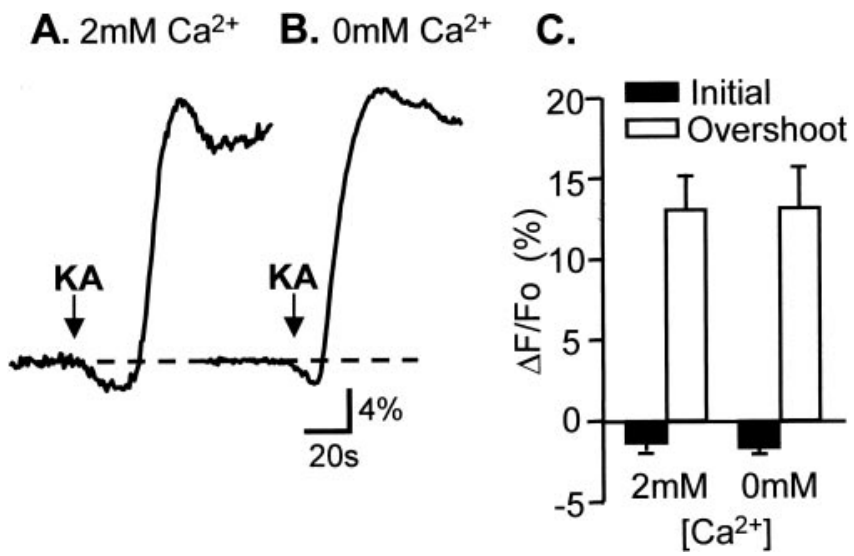

Figure 8. Extracellular $\mathrm{Ca}^{2+}$ removal had no significant effect on $\mathrm{NAD}(\mathrm{P}) \mathrm{H}$ fluorescence transients evoked by kainate stimulation. $A, B$, Representative single trials illustrating NAD(P)H fluorescence changes in s. pyramidale after exposure to a single bolus of kainate (at arrows). $C$, Mean data for six preparations ( \pm SEM) showing the initial deflection and overshoot responses. No significant differences were found for either component.

It is unlikely that $\mathrm{Ca}^{2+}$ influxes occurred after $>10 \mathrm{~min}$ in the $\mathrm{Ca}^{2+}$-free ACSF and even more so that they increased (to explain the increased overshoot after $2 \mathrm{~min}$ in zero $\mathrm{Ca}^{2+}$ ). However, $\mathrm{Ca}^{2+}$ and Rh123 changes in response to matched glutamate applications were examined to look for a possible intracellular $\mathrm{Ca}^{2+}$ release, or indication thereof, that might persist without $\mathrm{Ca}^{2+}$ influx. Figure $7 B$ (hatched bars) shows the effect of extracellular $\mathrm{Ca}^{2+}$ removal on fura-2 ratio signals. There was an appreciable $\mathrm{Ca}^{2+}$ transient after the first glutamate pulse delivered in the $\mathrm{Ca}^{2+}$-free ACSF, as might be expected from the time necessary to achieve low $\mathrm{Ca}^{2+}$ within the slice and also possibly from intracellular release primed by the previous $\mathrm{Ca}^{2+}$ loads (Pozzo-Miller et al., 1996). $\mathrm{Ca}^{2+}$ transients were reduced substantially after $7 \mathrm{~min}$ in zero $\mathrm{Ca}^{2+}$ and virtually were abolished 12 min after extracellular $\mathrm{Ca}^{2+}$ removal. A progressive downward shift in the resting baseline compared with normal $\mathrm{Ca}^{2+}(11.4 \pm 2.6 \%$ ratio decrease after $12 \mathrm{~min}$ exposure; $p<0.03 ; n=5$ ) was noted also.

Concurrent changes in Rh123 signals are illustrated in Figure 7C. With the reduced $\mathrm{Ca}^{2+}$ transients after removal of extracellular $\mathrm{Ca}^{2+}$ the amplitudes of Rh123 signals (indicating $\Psi_{\mathrm{m}}$ loss) during the glutamate activation were reduced substantially, but not abolished. Even after $12 \mathrm{~min}$ in zero $\mathrm{Ca}^{2+}$ a significant fraction of the Rh123 signal ( $\sim 30 \%$ ) persisted (Fig. $7 C$ ). The reduced Rh123 signals were not artifacts caused by loss of Rh123 from the cells during the several stimuli. $\mathrm{Ca}^{2+}$ restoration resulted in an increase in both the $\mathrm{Ca}^{2+}$ and $\Delta \Psi_{\mathrm{m}}$ to control levels $(61.0 \pm 11.9$ and $91.0 \pm 24.1 \%$ after 3 and 8 min restoration of $\mathrm{Ca}^{2+}$ for fura- $2 ; n=5 ; 67.9 \pm 18.7$ and $131.6 \pm 43.1 \%$ for Rh123).

The data of Figure 7 strongly suggest that neither component of evoked $\mathrm{NAD}(\mathrm{P}) \mathrm{H}$ changes requires intracellular $\mathrm{Ca}^{2+}$ increases. In fact, a depression of the overshoot with repetitive glutamate exposures occurs only with stimulation in normal $\mathrm{Ca}^{2+}$ / ACSF. Thus it appears that repetitive glutamate exposures lead to changes in the overshoot component of $\mathrm{NAD}(\mathrm{P}) \mathrm{H}$ transients, possibly via $\mathrm{Ca}^{2+}$ loading of mitochondria, but that neither component is reduced by the removal of extracellular $\mathrm{Ca}^{2+}$.

To investigate further the $\mathrm{Ca}^{2+}$ dependence of evoked $\mathrm{NAD}(\mathrm{P}) \mathrm{H}$ fluorescence responses, we examined the effects of the AMPA/kainate receptor agonist KA. KA was applied as a bolus to the perfusate, and previous work showed that this produces a large intracellular $\mathrm{Ca}^{2+}$ increase in murine slices (Shuttleworth 
and Connor, 2001). Figure $8 A$ shows that, like synaptic stimulation and glutamate iontophoresis, this brief KA exposure produced an initial $\mathrm{NAD}(\mathrm{P}) \mathrm{H}$ fluorescence decrease followed by a much larger overshoot. To test the involvement of $\mathrm{Ca}^{2+}$ changes, we compared responses in normal ACSF with responses in slices exposed to zero $\mathrm{Ca}^{2+}$ media for $10 \mathrm{~min}$ before KA exposure. From single-cell $\mathrm{Ca}^{2+}$-imaging studies we have found that responses to KA are abolished after $5 \mathrm{~min}$ of this procedure $(n=3$; data not shown). There was no significant difference in amplitude of overshoot or initial responses in zero $\mathrm{Ca}^{2+}$ (Fig. 8; $n=9$ each), suggesting that, as with glutamate iontophoresis, neuronal $\mathrm{Ca}^{2+}$ influx is not required for either component of evoked $\mathrm{NAD}(\mathrm{P}) \mathrm{H}$ transients.

\section{Contribution of $\mathrm{Na}^{+}$-dependent mechanisms}

The finding that $\mathrm{Ca}^{2+}$ removal had no significant effect on either component of evoked NAD $(\mathrm{P}) \mathrm{H}$ transients suggested that mitochondrial $\mathrm{Ca}^{2+}$ accumulation had little involvement in the transients observed in these mature slices. We therefore considered other types of coupling of neuronal activation to metabolism. ATP use during neuronal activation potentially can influence NADH levels by regulation of rates of oxidative phosphorylation and also of the TCA cycle (Stryer, 1988). A significant demand on ATP levels is made by activity of the plasmalemmal $\mathrm{Na}^{+} / \mathrm{K}^{+}$ ATPase during neuronal activity. The possible involvement of this pump in activity-dependent $\mathrm{NAD}(\mathrm{P}) \mathrm{H}$ transients was tested in two ways: (1) by pharmacological inhibition of $\mathrm{Na}^{+} / \mathrm{K}^{+}$ ATPase with the use of ouabain and (2) by reduction of $\mathrm{Na}^{+}$influx by substitution with $\mathrm{Li}^{+}$. Because both of these interventions can interfere with synaptic transmission mechanisms, this series of experiments used direct postsynaptic stimulation with glutamate microiontophoresis or brief KA exposures, as described above, for tests of $\mathrm{Ca}^{2+}$ dependence.

\section{Pharmacological inhibition of $\mathrm{Na}^{+} / \mathrm{K}^{+}$ATPase by ouabain}

Ouabain exposure $(30 \mu \mathrm{M})$ for $15 \mathrm{~min}$ completely abolished both components of $\mathrm{NAD}(\mathrm{P}) \mathrm{H}$ responses evoked by $\mathrm{KA}$ exposure $(n=5)$. This block could be taken as strong evidence for involvement of this pump in both components of $\mathrm{NAD}(\mathrm{P}) \mathrm{H}$ transients, but it is complicated by other effects of ouabain in the slice. It is well established that ouabain initiates spreading depression (SD) in hippocampal slices (Balestrino et al., 1999; Menna et al., 2000; Wu and Fisher, 2000; Xiong and Stringer, 2000), which results in a sustained decrease in tissue excitability. This phenomenon has been described with microelectrode recording (see above) and also in $\mathrm{NAD}(\mathrm{P}) \mathrm{H}$-imaging studies of pathologic $\mathrm{SD}$ waves in intact cortex (Mayevsky et al., 1998; Rex et al., 1999; Hashimoto et al., 2000; Strong et al., 2000). Indeed, we found that ouabain alone $(30 \mu \mathrm{M})$ resulted in a spreading depression-type phenomenon in eight of eight preparations that were tested. The event was characterized by a large propagating $\mathrm{NAD}(\mathrm{P}) \mathrm{H}$ decrease, followed by rapid overshoot that moved along the CA1 pyramidal cell layer (Fig. 9A,B). In the absence of other drugs SD was observed with a variable onset time after the initiation of ouabain exposure (mean, $9.9 \pm 0.9 \mathrm{~min}$; range, $7.1-11.7 \mathrm{~min}$ ). These results imply that a block of KA responses after 15 min ouabain exposures is confounded seriously by the initiation of SD.

Having determined the minimum expected onset time for ouabain-induced SD, we tested subsequent challenges at an earlier time point $(4.5 \mathrm{~min})$. We reasoned that, at this time point, $\mathrm{Na}^{+} / \mathrm{K}^{+}$ATPase should be reduced at least partially and that slices still would be excitable. KA proved unsuitable for this protocol, because this global stimulus accelerated the onset of SD
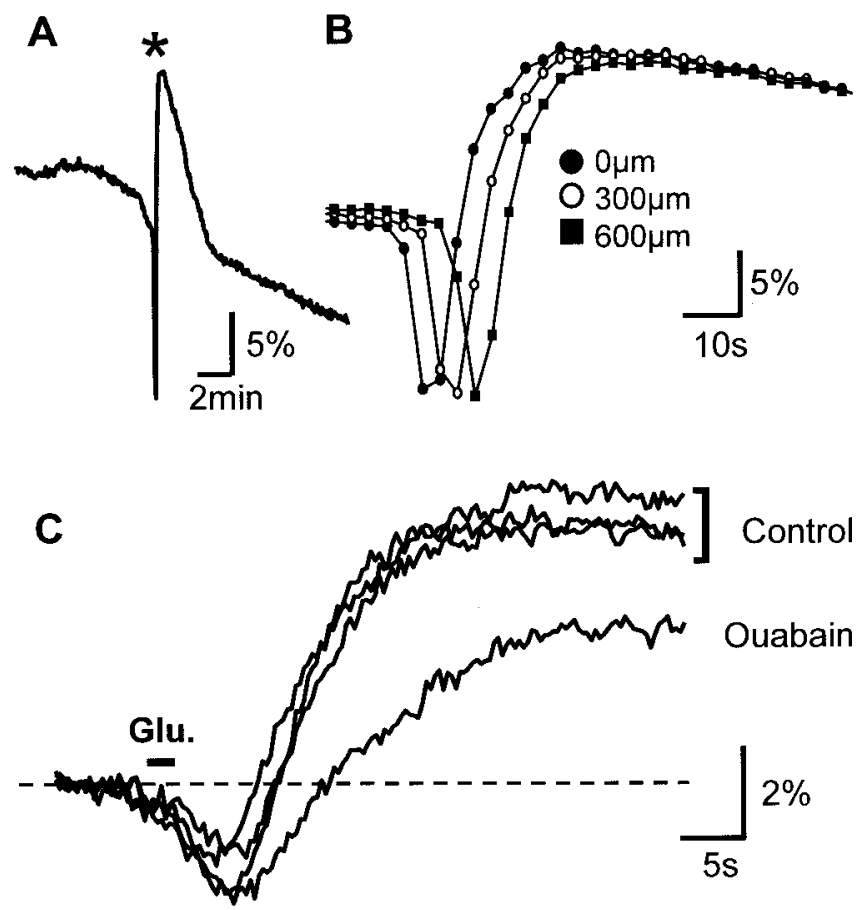

Figure 9. Effects of ouabain exposure on spontaneous and evoked NAD(P)H dynamics. $A$, Exposure to $30 \mu \mathrm{m}$ ouabain alone (beginning at start of trace) initiated a strong biphasic $\mathrm{NAD}(\mathrm{P}) \mathrm{H}$ response after $\sim 7.5 \mathrm{~min}$ of ouabain exposure (asterisk). $B$, Illustrated is the progression of this response along the CA1 pyramidal cell layer. The same event as in $A$ is shown at an expanded time base, recorded at three locations along the CA1 pyramidal cell layer. The characteristics of these responses are similar to those described previously for spreading depression (see Results). The onset of spreading depression required that the effects of ouabain on evoked $N A D(P) H$ responses be tested after very brief ouabain exposures. $C, N A D(P) H$ transients after glutamate iontophoresis are shown under control conditions (three trials, top traces) and after $4.5 \mathrm{~min}$ of ouabain exposure (bottom trace). Ouabain exposure decreased the overshoot component of the evoked response.

$(1.54 \pm 0.14 \mathrm{~min}$ after KA bolus addition; $n=6)$. Therefore, glutamate iontophoresis was used. To establish a baseline response, we made three applications of glutamate at $5 \mathrm{~min}$ intervals in normal ACSF. A fourth application was administered 5 min after the third, including a $4.5 \mathrm{~min}$ exposure to ouabain. $\mathrm{NAD}(\mathrm{P}) \mathrm{H}$ fluorescence levels, measured immediately before glutamate challenges, were not changed significantly by ouabain exposure alone $(112.9 \pm 4.3$ vs $112.8 \pm 4.2 \mathrm{AFU}$, control and ouabain, respectively; 100 msec exposures; $n=6$ ). Acceptance criteria for data were that both components of biphasic $\mathrm{NAD}(\mathrm{P}) \mathrm{H}$ transients were present in stratum pyramidale and that the three control responses showed $<10 \%$ variation $(n=3$ of 6 preparations tested). Figure $9 C$ shows one such data set in which the post-ouabain overshoot was reduced by $46 \%$ as compared with control responses, whereas the initial component mainly was unchanged. Measured $30 \mathrm{sec}$ after the glutamate stimulus, the mean $\mathrm{NAD}(\mathrm{P}) \mathrm{H}$ overshoot was reduced from $4.94 \pm$ 1.09 to $1.78 \pm 0.82 \%$ by ouabain exposure $(p<0.008 ; n=3)$, whereas the initial components of responses were not changed significantly ( $3.43 \pm 0.81$ and $3.50 \pm 0.45 \%, n=3$, for control and ouabain, respectively).

\section{Sodium replacement}

Lithium ions permeate $\mathrm{Na}^{+}$channels and ionotropic glutamate receptors and support action potential firing. However, $\mathrm{Li}^{+}$is a poor substrate for $\mathrm{Na}^{+} / \mathrm{K}^{+}$ATPase (Mullins, 1975) and thus allows neuronal activation while limiting changes in ATP/ADP 

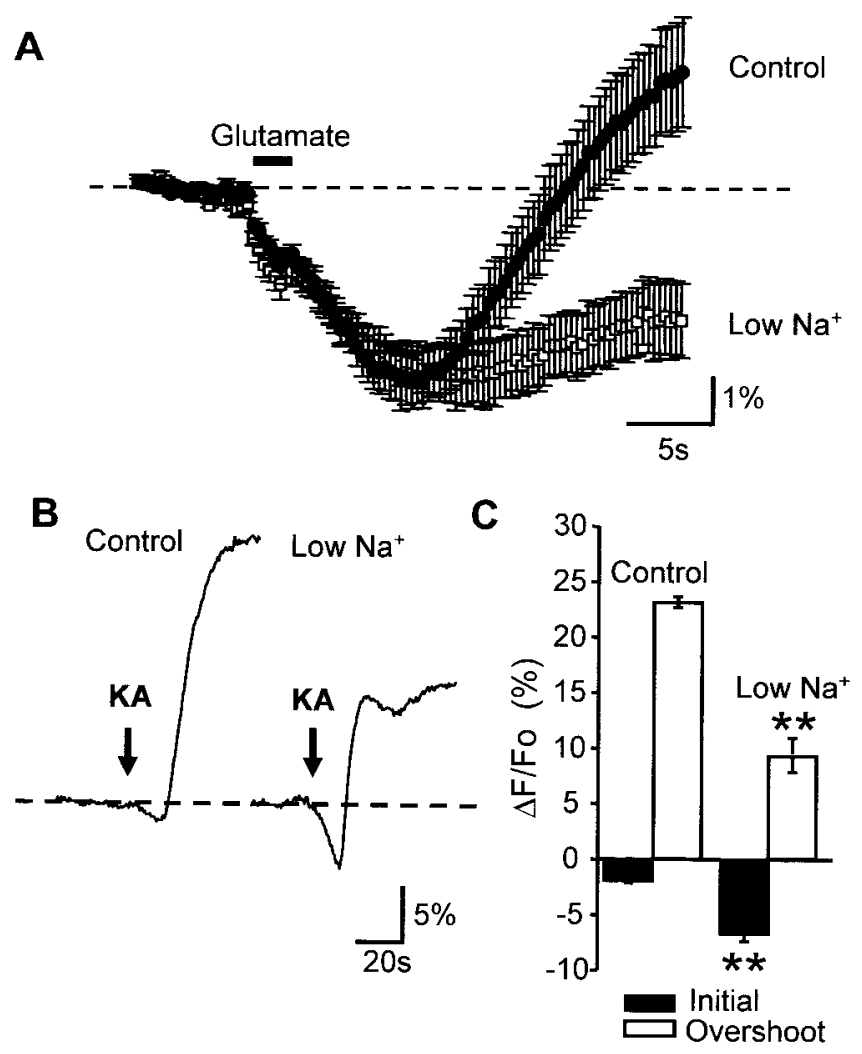

Figure 10. Reduction of extracellular $\left[\mathrm{Na}^{+}\right]$reduced stimulus-evoked $\mathrm{NAD}(\mathrm{P}) \mathrm{H}$ increases. $A$, Control $\operatorname{NAD}(\mathrm{P}) \mathrm{H}$ transients evoked by glutamate iontophoresis in $153 \mathrm{~mm}$ extracellular $\mathrm{Na}^{+}$ are indicated in filled circles. Reduction of extracellular $\mathrm{Na}^{+}$to $27 \mathrm{~mm}$ (open squares) significantly reduced the overshoot component, with no significant effect on the initial component of $\mathrm{NAD}(\mathrm{P}) \mathrm{H}$ transients ( $n=9$ for each). $B$, Effect of $\mathrm{Na}^{+}$reduction on responses to bolus $\mathrm{KA}$ exposure. KA applied at the arrows produced large biphasic transients, as shown previously in Figure 8. $\mathrm{Na}^{+}$reduction for 3 min led to a significant increase in the initial component and decrease in overshoot component of the response. $C$, Mean data ( \pm SEM) from four slices in normal ACSF and four slices in low $\mathrm{Na}^{+}\left({ }^{* *} p<0.0005\right)$.

ratios because of $\mathrm{Na}^{+} / \mathrm{K}^{+}$ATPase activity. We replaced $\mathrm{NaCl}$ with $\mathrm{LiCl}$, resulting in an $82.2 \%$ reduction of $\left[\mathrm{Na}^{+}\right]$in the bathing ACSF (from 153.25 to $27.25 \mathrm{~mm}$ ). Exposures to Li-ACSF were kept short $(<3 \mathrm{~min})$ to prevent secondary effects of $\mathrm{Na}^{+}$depletion such as loss of $\mathrm{Na}^{+}$-dependent transporter activity (Tong and Jahr, 1994). Fura-2 measurements during $\mathrm{Li}^{+}$substitution showed that intracellular $\mathrm{Ca}^{2+}$ remained at basal levels for $\sim 8$ min and then began to rise ( $n=3$ slices; data not shown), possibly because of impaired $\mathrm{Na}^{+}-\mathrm{Ca}^{2+}$ exchange or increases in ambient glutamate. As can be seen in Figure $10 \mathrm{~A}$, low-sodium ACSF resulted in a substantial reduction of the overshoot component of responses to glutamate iontophoresis. Responses in control ACSF were compared with responses 5 min later, including a 2.5 min preexposure to lithium ACSF. The amplitude of the overshoot was decreased significantly from an overshoot of $1.28 \pm$ $0.60 \%$ to a persistent $\mathrm{NAD}(\mathrm{P}) \mathrm{H}$ decrease of $2.08 \pm 0.63 \%$ (control and lithium, respectively; $p<0.005 ; n=9$ ). The amplitude of the initial $\mathrm{NAD}(\mathrm{P}) \mathrm{H}$ decrease was not significantly different (3.72 \pm 0.47 compared with $3.83 \pm 0.46 \%$, control and lithium, respectively; $p=0.85 ; n=9)$. Baseline $\mathrm{NAD}(\mathrm{P}) \mathrm{H}$ fluorescence levels, measured immediately before glutamate challenges, were not changed significantly by lithium substitution $(108.1 \pm 6.7 \mathrm{vs}$ $109.8 \pm 6.5$ AFU, control and lithium ACSF, respectively; 100 msec exposures; $n=9$ ). Likewise, responses to KA exposure showed a substantial decrease in overshoot response in reduced
$\mathrm{Na}^{+}$from $23.2 \pm 5$ to $9.4 \pm 1.5 \%$ (control and lithium, respectively; $p<0.0002$; Fig. $10 B, C$ ). Under these stimulus conditions the initial component was increased from $2.0 \pm 0.1$ to $6.7 \pm 0.7 \%$ (control and lithium, respectively; $p<0.0006 ; n=4$ ).

These results, taken together with the ouabain data, are consistent with the suggestion that the activity of $\mathrm{Na}^{+} / \mathrm{K}^{+}$ATPase and consequent increase in ADP/ATP ratio during neuronal activity strongly contribute to the overshoot component of the biphasic $\mathrm{NAD}(\mathrm{P}) \mathrm{H}$ transients. The initial $\mathrm{NAD}(\mathrm{P}) \mathrm{H}$ decrease was not reduced by these procedures. This could be attributable to the fact that it is difficult to obtain a complete block of ATP use by this pump without significant deleterious consequences on slice excitability. From other results in this study it is evident that the initial NADH oxidation is the more prominent feature of small metabolic demands, as in limited spike generation in normal ACSF, whereas the overshoot is more prominent as stimulus intensity is increased or the number of spikes increased by bicuculline exposure (see Fig. 3). Thus as ATP use is reduced for large stimuli by the substitution of $\mathrm{Li}^{+}$influx for $\mathrm{Na}^{+}$, the NAD(P)H fluorescence signal should revert to the small load format, with a preferential reduction in the overshoot component. However, it also remains possible that the initial $\mathrm{NAD}(\mathrm{P}) \mathrm{H}$ decrease may be attributable to other coupling of neuronal activity to NADH levels independent of plasmalemmal $\mathrm{Na}^{+} / \mathrm{K}^{+}$ATPase activity.

\section{Discussion}

We draw three main conclusions from the present results. First, $\mathrm{CCD}$ imaging of $\mathrm{NAD}(\mathrm{P}) \mathrm{H}$ fluorescence changes provides a robust, noninvasive indicator of postsynaptic neuronal activation in hippocampal slices. The method is capable of detecting localized evoked activity that lies well within the range of normal physiology. Second, maps of the optical signals show that the two components of biphasic $\mathrm{NAD}(\mathrm{P}) \mathrm{H}$ responses show locationdependent differential expression; thus the two components may not be linked inextricably. Third, NAD $(\mathrm{P}) \mathrm{H}$ fluorescence changes in the mature slices studied here are not a consequence of neuronal $\mathrm{Ca}^{2+}$ accumulation (Figs. 7, 8) but reflect the coupling of other metabolic demands, including increased activity of $\mathrm{Na}^{+} / \mathrm{K}^{+}$ATPase, which accompanies postsynaptic activation.

\section{$\mathrm{NAD}(\mathrm{P}) \mathrm{H}$ imaging of neuronal activation}

The present study indicates that robust $\mathrm{NAD}(\mathrm{P}) \mathrm{H}$ changes do not require intense or pathological neuronal activation. $\mathrm{NAD}(\mathrm{P}) \mathrm{H}$ transients evoked by short stimulus trains were of the order of $3-8 \%$ in amplitude, were resolved readily in single trials, and could be evoked repetitively for many hours without appreciable decrement. In the presence of bicuculline even responses to single presynaptic shocks could be resolved easily in a single trial (Fig. 1 ). As might be expected, the averaging of multiple trials enhanced detection of responses to very low intensity stimuli (data not shown). Stimulation also produced a fluorescence change for which the characteristic wavelengths were appropriate for FAD oxidation. These data suggest that relatively large, reproducible demands on oxidative phosphorylation in slice can be imaged during normal synaptic physiology. This would not preclude the involvement of other, perhaps more pathologic, mechanisms (e.g., mitochondrial permeability transition, ROS production) that might occur during seizures or ischemia (Reynolds, 1999; Kovacs et al., 2001; Schuchmann et al., 2001).

The finding that both components of synaptically evoked $\mathrm{NAD}(\mathrm{P}) \mathrm{H}$ transients were abolished by a combination of ionotropic glutamate receptor antagonists implies that the responses result from postsynaptic metabolic loads. It also implies that 
other metabolic loads introduced by presynaptic activation, such as energy-consuming reuptake and processing of glutamate by glial cells (Magistretti et al., 1999), make only a minor contribution to the observed responses, because there was not an appreciable residual response after glutamate receptor block. This is not to say that the $\mathrm{NAD}(\mathrm{P}) \mathrm{H}$ fluorescence changes in slice originate entirely in neurons. Neuronal electrical activity causes a sizable increase in extracellular $\mathrm{K}^{+}$, which is taken up at least in part by glial cells (Hounsgaard and Nicholson, 1983) at the expense of increased ATP consumption. We have not examined glial $\mathrm{Ca}^{2+}$ dynamics in this study directly, and such signaling potentially could contribute to $\mathrm{NAD}(\mathrm{P}) \mathrm{H}$ changes in the slice preparation also. The large increase in the optical response brought about by $\mathrm{GABA}_{\mathrm{A}}$ receptor block is consistent with increased postsynaptic excitation for a given stimulus strength (Grinvald et al., 1982), which would increase metabolic demand in both neurons and glia.

\section{Discrimination of components of biphasic responses}

For the most part $\mathrm{NAD}(\mathrm{P}) \mathrm{H}$ fluorescence measurements have been made by using single detectors or in some cases multiple detectors coupled to optic fibers (Mayevsky et al., 1988). Higherresolution devices such as CCD cameras have been used to monitor the slow spread of large changes that occur during spreading depression-like events (Hashimoto et al., 2000; Strong et al., 2000) in intact cortex and during bursting activity in respiratory neurons in brainstem slices (Mironov and Richter, 2001). In the present study this approach enabled monitoring of activity within an extended area of CA1 while maintaining adequate temporal resolution (up to $18 \mathrm{~Hz}$ ) for reliable assessment of both fast and slow components of evoked $\mathrm{NAD}(\mathrm{P}) \mathrm{H}$ transients. With lowintensity electrical stimuli (Fig. 2) or localized glutamate application (Fig. 6), excitation could be seen to initiate in regions close to the stimulus electrode and spread through a discrete region of the of the CA1 pyramidal cell layer. Depending on the stimulus strength, the response could be restricted to s. radiatum and $s$. pyramidale or could involve more extensive regions, including s. oriens.

A surprising finding that emerged from these studies was that the spatial profiles of the two components were not always matched. We had expected that the same metabolism-linked changes would trigger both initial $\mathrm{NAD}(\mathrm{P}) \mathrm{H}$ decreases and subsequent $\mathrm{NAD}(\mathrm{P}) \mathrm{H}$ overshoots, predicting that the largest decreases would occur at the sites of most intense neuronal activation (typically close to the stimulus electrode) and that, after termination of the stimulus, mechanisms responsible for regenerating NADH levels would be activated most intensely at this same location. This would result in matched spatial profiles of the two components of biphasic responses. This was found generally to be the case when electrical stimuli were applied to s. radiatum. However, after stimulation at the alveus the largest initial decrease occurred in the region of basal dendrites, but the largest overshoot occurred in s. radiatum. Application of glutamate over the pyramidal cell layer also produced the largest initial $\mathrm{NAD}(\mathrm{P}) \mathrm{H}$ decreases in basal dendritic regions, with large overshoots occurring in the apical dendritic area. A number of factors could contribute to differential expression of $\mathrm{NAD}(\mathrm{P}) \mathrm{H}$ decreases and increases in different hippocampal subfields and are the subject of future work. However, these observations do suggest that the compound $\mathrm{NAD}(\mathrm{P}) \mathrm{H}$ responses do not reflect an obligatory coupling between an $\mathrm{NAD}(\mathrm{P}) \mathrm{H}$ decrease and any subsequent increase. This also suggests that integrated area measurements, as are obtained with photo multiplier tubes or photodiodes, can be misleading in that where a large area is observed, the signal is a mixture of components that may have quite different kinetics and spatial distributions. These considerations need to be taken into account if $\mathrm{NAD}(\mathrm{P}) \mathrm{H}$ fluorescence measurements are used for mapping neuron activation, because the characteristics of initial $\mathrm{NAD}(\mathrm{P}) \mathrm{H}$ decreases can be influenced strongly by the differential emergence of $\mathrm{NAD}(\mathrm{P}) \mathrm{H}$ overshoots in different locations (Fig. 4B).

\section{$\mathrm{Ca}^{2+}$ independence of evoked $\mathrm{NAD}(\mathrm{P}) \mathrm{H}$ transients}

As far as we are aware, the present study is the first to examine the $\mathrm{Ca}^{2+}$ dependence of these signals in slice, and we found that even protracted removal of extracellular $\mathrm{Ca}^{2+}$ and the consequent block of $\mathrm{Ca}^{2+}$ transients did not diminish evoked $\mathrm{NAD}(\mathrm{P}) \mathrm{H}$ transients (Figs. 7, 8). This strongly suggests that, in this preparation, the largest demands on oxidative metabolism are consequences of ionic fluxes other than $\mathrm{Ca}^{2+}$ (e.g., $\mathrm{Na}^{+}$and $\mathrm{K}^{+}$). Our observations with ouabain exposure and extracellular $\mathrm{Na}^{+}$reduction (Figs. 9, 10) suggest that activity of plasmalemmal $\mathrm{Na}^{+} / \mathrm{K}^{+}$ATPase contributes significantly to NAD (P)H signals in mature slices. This observation supports an earlier proposal that decreases in NADH fluorescence observed after hippocampal stimulation in vivo were primarily a consequence of ATP depletion by active transport (Lewis and Schuette, 1973). Changes in ADP/ATP ratio could underlie biphasic $\mathrm{NAD}(\mathrm{P}) \mathrm{H}$ transients by direct coupling to an increased oxidative phosphorylation rate, as well as stimulation of enzymes of the TCA cycle to produce longer-lasting NADH increases (Crompton, 1990; Brandes and Bers, 1999). Intracellular $\mathrm{Ca}^{2+}$ increases and mitochondrial depolarization certainly occur during hippocampal depolarization (Figs. 5, 7), but we argue that this occurs as a parallel consequence of membrane depolarization and is not required for the $\mathrm{NAD}(\mathrm{P}) \mathrm{H}$ transients that have been imaged here.

These conclusions provide a significant contrast to recent suggestions that mitochondrial $\mathrm{Ca}^{2+}$ dynamics underlie $\mathrm{NAD}(\mathrm{P}) \mathrm{H}$ transients in hippocampal slices and bring into question the utility of $\mathrm{NAD}(\mathrm{P}) \mathrm{H}$ fluorescence as a convenient, noninvasive indicator of mitochondrial $\mathrm{Ca}^{2+}$ loading in these preparations. The pivotal study of Duchen (1992), performed in isolated dorsal root ganglion neurons, clearly showed that removal of extracellular $\mathrm{Ca}^{2+}$ abolished biphasic $\mathrm{NAD}(\mathrm{P}) \mathrm{H}$ responses to plasma membrane depolarization. The stimulus protocol was a sustained $\mathrm{K}^{+}$ depolarization that under normal conditions produced a large $\mathrm{Ca}^{2+}$ rise and significant mitochondrial depolarization. We suggest that the discrepancy between conclusions of the current study and previous work may arise from differences in ion fluxes in the two sets of experiments. During sustained depolarizations in young DRG neurons the $\mathrm{Na}^{+}$channels rapidly inactivate, preventing the firing of multiple action potentials (Chen et al., 1987). However, in DRG neurons the $\mathrm{Ca}^{2+}$ influx is sustained via highthreshold slowly inactivating voltage-dependent $\mathrm{Ca}^{2+}$ channels during extended depolarizations (Rane et al., 1987). In contrast, hippocampal pyramidal neurons in slice have major routes of $\mathrm{Na}^{+}$influx (AMPA/KA, NMDA receptors, and $\mathrm{Na}^{+}$channels) that are activated by glutamate or KA. These cells fire sustained bursts of action potentials after glutamate or kainate application (Shuttleworth and Connor, 2001) that can perturb intracellular concentrations of $\mathrm{Na}^{+}$significantly (Jaffe et al., 1992) and, to a lesser extent, $\mathrm{K}^{+}$. Removal of $\mathrm{Ca}^{2+}$ has little effect on this activation and actually may enhance the $\mathrm{Na}^{+}$load and $\mathrm{K}^{+}$deficit by reducing $\mathrm{Ca}^{2+}$-dependent spike frequency adaptation (Hotson and Prince, 1980). Thus the ionic basis for ATP use (because of the activity of pumps and sequestration mechanisms) that follows excitation of hippocampal neurons and isolated DRGs is 
likely to be quite different and may explain the different conclusions about dependence on extracellular $\mathrm{Ca}^{2+}$. Although these findings suggest that evoked $\mathrm{NAD}(\mathrm{P}) \mathrm{H}$ transients in slice do not reflect mitochondrial $\mathrm{Ca}^{2+}$ dynamics, they do not rule out contributions from $\mathrm{Ca}^{2+}$-dependent regulation of NADH signals under other, more extreme, conditions, e.g., spreading depression or anoxia (Perez-Pinzon et al., 1998).

\section{References}

Balestrino M, Young J, Aitken P (1999) Block of $\left(\mathrm{Na}^{+}, \mathrm{K}^{+}\right)$ATPase with ouabain induces spreading depression-like depolarization in hippocampal slices. Brain Res 838:37-44.

Bindokas VP, Lee CC, Colmers WF, Miller RJ (1998) Changes in mitochondrial function resulting from synaptic activity in the rat hippocampal slice. J Neurosci 18:4570-4587.

Blasdel GG, Salama G (1986) Voltage-sensitive dyes reveal a modular organization in monkey striate cortex. Nature 321:579-585.

Brandes R, Bers DM (1999) Analysis of the mechanisms of mitochondrial NADH regulation in cardiac trabeculae. Biophys J 77:1666-1682.

Chance B, Cohen P, Jöbsis F, Schoener B (1962) Intracellular oxidationreduction states in vivo. Science 137:499-508.

Chen GG, Cole AE, MacDermott AB, Lange GD, Barker JL (1987) The influence of skeletal muscle on the electrical excitability of dorsal root ganglion neurons in culture. J Neurosci 7:2412-2422.

Cohen LB, Keynes RD, Hille B (1968) Light scattering and birefringence changes during nerve activity. Nature 218:438-441.

Cohen LB, Salzberg BM, Davila HV, Ross WN, Landowne D, Waggoner AS, Wang CH (1974) Changes in axon fluorescence during activity: molecular probes of membrane potential. J Membr Biol 19:1-36.

Connor JA, Kreulen DL, Prosser CL (1976) Relation between oxidative metabolism and slow rhythmic potentials in mammalian intestinal muscle. Proc Natl Acad Sci USA 73:4239-4243.

Connor JA, Razani-Boroujerdi S, Greenwood AC, Cormier RJ, Petrozzino JJ, Lin RCS (1999) Reduced voltage-dependent $\mathrm{Ca}^{2+}$ signaling in CA1 neurons after brief ischemia in gerbils. J Neurophysiol 81:299-306.

Crompton M (1990) The role of $\mathrm{Ca}^{2+}$ in the function and dysfunction of heart mitochondria. In: Calcium and the heart (Langer GA, ed), pp 167199. New York: Raven.

Duchen MR (1992) $\mathrm{Ca}^{2+}$-dependent changes in the mitochondrial energetics in single dissociated mouse sensory neurons. Biochem J 283:41-50.

Duchen MR, Smith PA, Ashcroft FM (1993) Substrate-dependent changes in mitochondrial function, intracellular free calcium concentration, and membrane channels in pancreatic $\beta$-cells. Biochem J 294:35-42.

Frostig RD, Lieke EE, Ts'o DY, Grinvald A (1990) Cortical functional architecture and local coupling between neuronal activity and the microcirculation revealed by in vivo high-resolution optical imaging of intrinsic signals. Proc Natl Acad Sci USA 87:6082-6086.

Grinvald A, Manker A, Segal M (1982) Visualization of the spread of electrical activity in rat hippocampal slices by voltage-sensitive optical probes. J Physiol (Lond) 333:269-291.

Grinvald A, Lieke E, Frostig RD, Gilbert CD, Wiesel TN (1986) Functional architecture of cortex revealed by optical imaging of intrinsic signals. Nature 324:361-364.

Hajnoczky G, Robb-Gaspers LD, Seitz MB, Thomas AP (1995) Decoding of cytosolic calcium oscillations in the mitochondria. Cell 82:415-424.

Hashimoto M, Takeda Y, Sato T, Kawahara H, Nagano O, Hirakawa M (2000) Dynamic changes of NADH fluorescence images and NADH content during spreading depression in the cerebral cortex of gerbils. Brain Res 872:294-300.

Hill DK, Keynes RD (1949) Opacity changes in stimulated nerve. J Physiol (Lond) 108:278-281.

Hotson JR, Prince DA (1980) A calcium-activated hyperpolarization follows repetitive firing in hippocampal neurons. J Neurophysiol 43:409-419.

Hounsgaard J, Nicholson C (1983) Potassium accumulation around individual Purkinje cells in cerebellar slices from the guinea-pig. J Physiol (Lond) 340:359-388

Jaffe DB, Johnston D, Lasser-Ross N, Lisman JE, Miyakawa H, Ross WN (1992) The spread of $\mathrm{Na}^{+}$spikes determines the pattern of dendritic $\mathrm{Ca}^{2+}$ entry into hippocampal neurons. Nature 357:244-246.

Jöbsis FF, O'Connor M, Vitale A, Vreman H (1971) Intracellular redox changes in functioning cerebral cortex. I. Metabolic effects of epileptiform activity. J Neurophysiol 4:735-749.

Kovacs R, Schuchmann S, Gabriel S, Kardos J, Heinemann U (2001) $\mathrm{Ca}^{2+}$ signaling and changes of mitochondrial function during low- $\mathrm{Mg}^{2+}$ induced epileptiform activity in organotypic hippocampal slice cultures. Eur J Neurosci 13:1311-1319.

Lewis DV, Schuette WH (1973) NADH fluorescence and $\left[\mathrm{K}^{+}\right]_{\mathrm{o}}$ changes during hippocampal electrical stimulation. J Neurophysiol 38:405-417.

Loew LM, Carrington W, Tuft RA, Fay FS (1994) Physiological cytosolic $\mathrm{Ca}^{2+}$ transients evoke concurrent mitochondrial depolarizations. Proc Natl Acad Sci USA 91:12579-12583.

Luo M, Katz LC (2001) Response correlation maps of neurons in the mammalian olfactory bulb. Neuron 32:1165-1179.

MacVicar BA, Hochman D (1991) Imaging of synaptically evoked intrinsic optical signals in hippocampal slices. J Neurosci 11:1458-1469.

Magistretti PJ, Pellerin L, Rothman DL, Shulman RG (1999) Energy on demand. Science 283:496-497.

Mayevsky A, Nioka S, Chance B (1988) Fiber optic surface fluorometry/ reflectometry and 31-p-NMR for monitoring the intracellular energy state in vivo. Adv Exp Med Biol 222:365-374.

Mayevsky A, Meilin S, Manor T, Ornstein E, Zarchin N, Sonn J (1998) Multiparametric monitoring of brain oxygen balance under experimental and clinical conditions. Neurol Res 20:S76-S80.

McCormack JG, Denton RM (1993) Mitochondrial $\mathrm{Ca}^{2+}$ transport and the role of intramitochondrial $\mathrm{Ca}^{2+}$ in the regulation of energy metabolism. Dev Neurosci 15:165-173.

Menna G, Tong CK, Chesler M (2000) Extracellular pH changes and accompanying cation shifts during ouabain-induced spreading depression. J Neurophysiol 83:1338-1345.

Mironov SL, Richter DW (2001) Oscillations and hypoxic changes of mitochondrial variables in neurons of the brainstem respiratory centre of mice. J Physiol (Lond) 33:227-236.

Müller W, Connor JA (1991) Cholinergic input uncouples $\mathrm{Ca}^{2+}$ changes from $\mathrm{K}^{+}$conductance activation and amplifies intradendritic $\mathrm{Ca}^{2+}$ changes in hippocampal neurons. Neuron 6:901-905.

Mullins LJ (1975) Ion selectivity of carriers and channels. Biophys J 15:921-931.

O’Connor MJ, Herman CJ, Rosenthal M, Jöbsis FF (1972) Intracellular redox changes preceding onset of epileptiform activity in intact cat hippocampus. J Neurophysiol 35:471-483.

Perez-Pinzon MA, Mumford PL, Carranza V, Sick TJ (1998) Calcium influx from the extracellular space promotes NADH hyperoxidation and electrical dysfunction after anoxia in hippocampal slices. J Cereb Blood Flow Metab 18:215-221.

Pitter JG, Maechler P, Wollheim CB, Spat A (2002) Mitochondria respond to $\mathrm{Ca}^{2+}$ already in the submicromolar range: correlation with redox state. Cell Calcium 31:97-104.

Pozzo-Miller LD, Petrozzino JJ, Golarai G, Connor JA (1996) $\mathrm{Ca}^{2+}$ release from intracellular stores induced by afferent stimulation of CA3 pyramidal neurons in hippocampal slices. J Neurophysiol 76:554-562.

Pralong WF, Hunyady L, Varnai P, Wollheim CB, Spat A (1992) Pyridine nucleotide redox state parallels production of aldosterone in potassiumstimulated adrenal glomerulosa cells. Proc Natl Acad Sci USA 89:132-136.

Rane SG, Holz GG, Dunlap K (1987) Dihydropyridine inhibition of neuronal calcium current and substance P release. Pfl $\int$ gers Arch 409:361-366.

Regehr WG, Tank DW (1991) Selective fura-2 loading of presynaptic terminals and nerve cell processes by local perfusion in mammalian brain slice. J Neurosci Methods 37:111-119.

Rex A, Pfeifer L, Fink F, Fink H (1999) Cortical NADH during pharmacological manipulations of the respiratory chain and spreading depression in vivo. J Neurosci Res 57:359-370.

Reynolds IJ (1999) Mitochondrial membrane potential and the permeability transition in excitotoxicity. Ann NY Acad Sci 893:33-41.

Rohacs T, Tory K, Dobos A, Spat A (1997) Intracellular calcium release is more efficient than calcium influx in stimulating mitochondrial NADPH formation in adrenal glomerulosa cells. Biochem J 328:525-528.

Salzberg BM (1989) Optical recording of voltage changes in nerve terminals and in fine neuronal processes. Annu Rev Physiol 51:507-526.

Salzberg BM, Obaid AL, Gainer H (1985) Large and rapid changes in light scattering accompany secretion by nerve terminals in the mammalian neurohypophysis. J Gen Physiol 86:395-411. 
Schuchmann S, Buchheim K, Meierkord H, Heinemann U (1999) A relative energy failure is associated with low- $\mathrm{Mg}^{2+}$ but not with 4-aminopyridineinduced seizure-like events in entorhinal cortex. J Neurophysiol 81:399-403.

Schuchmann S, Luckermann M, Kulik A, Heinemann U, Ballanyi K (2000) $\mathrm{Ca}^{2+}$ - and metabolism-related changes of mitochondrial potential in voltage-clamped CA1 pyramidal neurons in situ. J Neurophysiol 83:1710-1721.

Schuchmann S, Kovacs R, Kann O, Heinemann U, Buchheim K (2001) Monitoring NADPH autofluorescence to assess mitochondrial metabolic functions in rat hippocampal-entorhinal cortex slices. Brain Res Brain Res Protoc 7:267-276.

Shoham D, Glaser DE, Arieli A, Kenet T, Wijnbergen C, Toledo Y, Hildesheim R, Grinvald A (1999) Imaging cortical dynamics at high spatial and temporal resolution with novel blue voltage-sensitive dyes. Neuron 24:791-802.

Shuttleworth CW, Connor JA (2001) Strain-dependent differences in calcium signaling predict excitotoxicity in murine hippocampal neurons. J Neurosci 21:4225-4236.

Strong AJ, Smith SE, Whittington DJ, Meldrum BS, Parsons AA, Krupinski J, Hunter AJ, Patel S (2000) Factors influencing the frequency of fluores- cence transients as markers of peri-infarct depolarizations in focal cerebral ischemia. Stroke 31:214-222.

Stryer L (1988) Biochemistry, 3rd Ed, pp 390, 421. New York: Freeman.

Swanson LW, Kohler C, Bjorklund A (1989) The limbic region. In: Integrated systems of the CNS, Pt I, The septohippocampal system, Chap 2 (Bjorklund A, Hokfelt T, Swanson LW, eds), pp 125-279. New York: Elsevier.

Tong G, Jahr CE (1994) Block of glutamate transporters potentiates postsynaptic excitation. Neuron 13:1195-1203.

Voronina S, Sukhomlin T, Johnson PR, Erdemli G, Petersen OH, Tepikin A (2002) Correlation of NADH and $\mathrm{Ca}^{2+}$ signals in mouse pancreatic acinar cells. J Physiol (Lond) 539:41-52.

White RJ, Reynolds IJ (1997) Mitochondria accumulate $\mathrm{Ca}^{2+}$ following intense glutamate stimulation of cultured rat forebrain neurones. J Physiol (Lond) 498:31-47.

Wu J, Fisher RS (2000) Hyperthermic spreading depressions in the immature rat hippocampal slice. J Neurophysiol 84:1355-1360.

Xiong ZQ, Stringer JL (2000) Sodium pump activity, not glial spatial buffering, clears potassium after epileptiform activity induced in the dentate gyrus. J Neurophysiol 83:1443-1451. 